\title{
The oxycoal process with cryogenic oxygen supply
}

\author{
Alfons Kather • Günter Scheffknecht
}

Received: 26 September 2008 /Revised: 15 April 2009 / Accepted: 13 May 2009 /Published online: 4 June 2009

(C) The Author(s) 2009. This article is published with open access at Springerlink.com

\begin{abstract}
Due to its large reserves, coal is expected to continue to play an important role in the future. However, specific and absolute $\mathrm{CO}_{2}$ emissions are among the highest when burning coal for power generation. Therefore, the capture of $\mathrm{CO}_{2}$ from power plants may contribute significantly in reducing global $\mathrm{CO}_{2}$ emissions. This review deals with the oxyfuel process, where pure oxygen is used for burning coal, resulting in a flue gas with high $\mathrm{CO}_{2}$ concentrations. After further conditioning, the highly concentrated $\mathrm{CO}_{2}$ is compressed and transported in the liquid state to, for example, geological storages. The enormous oxygen demand is generated in an airseparation unit by a cryogenic process, which is the only available state-of-the-art technology. The generation of oxygen and the purification and liquefaction of the $\mathrm{CO}_{2}$ enriched flue gas consumes significant auxiliary power. Therefore, the overall net efficiency is expected to be lowered by 8 to 12 percentage points, corresponding to a 21 to $36 \%$ increase in fuel consumption. Oxygen combustion is associated with higher temperatures compared with conventional air combustion. Both the fuel properties as well as limitations of steam and metal temperatures of the various heat exchanger sections of the steam generator require a moderation of the temperatures during combustion and in the subsequent heat-transfer sections. This is done by
\end{abstract}

A. Kather

Institute of Energy Systems, Hamburg University of Technology,

Hamburg, Germany

G. Scheffknecht $(\square)$

Institute of Process Engineering and Power

Plant Technology_IVD, Universität Stuttgart,

Stuttgart, Germany

e-mail: guenter.scheffknecht@ivd.uni-stuttgart.de means of flue gas recirculation. The interdependencies among fuel properties, the amount and the temperature of the recycled flue gas, and the resulting oxygen concentration in the combustion atmosphere are investigated. Expected effects of the modified flue gas composition in comparison with the air-fired case are studied theoretically and experimentally. The different atmosphere resulting from oxygen-fired combustion gives rise to various questions related to firing, in particular, with regard to the combustion mechanism, pollutant reduction, the risk of corrosion, and the properties of the fly ash or the deposits that form. In particular, detailed nitrogen and sulphur chemistry was investigated by combustion tests in a laboratory-scale facility. Oxidant staging, in order to reduce NO formation, turned out to work with similar effectiveness as for conventional air combustion. With regard to sulphur, a considerable increase in the $\mathrm{SO}_{2}$ concentration was found, as expected. However, the $\mathrm{H}_{2} \mathrm{~S}$ concentration in the combustion atmosphere increased as well. Further results were achieved with a pilot-scale test facility, where acid dew points were measured and deposition probes were exposed to the combustion environment. Besides $\mathrm{CO}_{2}$ and water vapour, the flue gas contains impurities like sulphur species, nitrogen oxides, argon, nitrogen, and oxygen. The $\mathrm{CO}_{2}$ liquefaction is strongly affected by these impurities in terms of the auxiliary power requirement and the $\mathrm{CO}_{2}$ capture rate. Furthermore, the impurity of the liquefied $\mathrm{CO}_{2}$ is affected as well. Since the requirements on the liquid $\mathrm{CO}_{2}$ with regard to geological storage or enhanced oil recovery are currently undefined, the effects of possible flue gas treatment and the design of the liquefaction plant are studied over a wide range.

Keywords Oxyfuel $\cdot$ Emissions $\cdot \mathrm{CO}_{2} \cdot$ Carbon capture 


\section{Introduction}

Now that emissions of dust, $\mathrm{NO}_{X}$, and $\mathrm{SO}_{2}$ in electric power generation from fossil primary energy sources have been reduced remarkably in the last few decades with the deployment and retrofitting of electrostatic precipitators (ESPs), $\mathrm{DeNO}_{X}$ reactors, and flue gas desulphurisation systems, the reduction of $\mathrm{CO}_{2}$ emissions has been assigned priority in the power generation industry since the beginning of the 1990s. Two means are being pursued to achieve this reduction in $\mathrm{CO}_{2}$ emissions in electric power generation from fossil primary energy sources:

- Efficiency improvement; and

- Separation of $\mathrm{CO}_{2}$ from fuel or flue gases.

Efficiency-improving measures help to further reduce $\mathrm{CO}_{2}$ emissions from today's fossil-fired power stations in Germany by approx. $25 \%$. For $\mathrm{CO}_{2}$ emission reduction targets that go beyond this, the question arises with regard to which methods can be used to separate the generated $\mathrm{CO}_{2}$ as completely as possible.

The development of these separation methods naturally concentrates on power plant processes that use coal as their primary energy source, due to the future availability of coal worldwide. Furthermore, the $\mathrm{CO}_{2}$ emissions are particularly high in the case of power generation from coal, which means that separating $\mathrm{CO}_{2}$ will enable even greater reductions in $\mathrm{CO}_{2}$ emissions. However, depending on the separation method and the power plant type, considerable efficiency losses result. These are currently in the range of $9 \%$ to $13 \%$ points (with the unit \% point an absolute efficiency loss is defined, i.e. a state-of-the-art pulverised fuel (PF) steam power plant with $46 \%$ efficiency lower heating value (LHV) has to be compared with a carbon-capture plant with an efficiency of 33 to 37) based on a state-of-the-art PF steam power plant, but it is likely that they can be reduced by means of other process optimisations to between $7 \%$ and $11 \%$ points.

In the case of the steam power cycle with a coal-fired furnace that is used most frequently for electric power generation, the $\mathrm{CO}_{2}$ could soon be scrubbed out of the flue gas using a monoethanolamine scrubber (Aroonwilas and Veawab 2006; Kather et al. 2008). The relatively low $\mathrm{CO}_{2}$ concentration of only $15 \mathrm{vol} \%$ in the wet flue gas means that this involves considerable energy input. As the largest portion of the remaining flue gas components consists of the atmospheric nitrogen introduced into the process with the combustion air, holding back this nitrogen before combustion ensures a significant increase in the $\mathrm{CO}_{2}$ concentration. This is why the concept underlying the oxyfuel process is to extract the nitrogen from the combustion air prior to combustion by means of an airseparation unit (ASU), which means that virtually pure oxygen is fed to the combustion process.
This review only discusses the coal-fired oxyfuel process that makes use of proven thermal power plant technology, where possible. From the viewpoint of the authors, this process enables rapid implementation, which is not only a result of using mature components. Other oxyfuel methods, for example, those that integrate high-temperature membranes to separate the air or are based on other cycles and are only suitable to a limited extent for use with coal, will not be discussed, due to them being unavailable in the near future and having an uncertain economic efficiency.

In the case of conventional air combustion, the atmospheric nitrogen is the major heat sink. In the case of the oxyfuel process, cooled flue gases are used as the heat sink instead of atmospheric nitrogen. In order to obtain a temperature level in the furnace that is similar to that in the case of combustion with air, around two thirds of the flue gases must be recycled to the furnace after being cooled down. Ideally, the flue gas would then only consist of the combustion products $\mathrm{CO}_{2}$ and steam resulting in pure $\mathrm{CO}_{2}$ after dehumidification. As will be explained later, the flue gas contains, however, not only $\mathrm{CO}_{2}$ and steam but also other components, leading to a $\mathrm{CO}_{2}$ concentration of 90 vol.\% at best after dehumidification. In Fig. 1, the flue gas leaving the steam generator has a $\mathrm{CO}_{2}$ content of approximately 89 vol.\% after complete dehumidification. The remaining ballast gas consists essentially of excess oxygen that is necessary not only for adequate burnout of the coal but also for reducing the risk of corrosion on the furnace walls. Furthermore, the ballast gas contains argon and nitrogen as well as sulphur species and nitrogen oxides.

These impurities in the $\mathrm{CO}_{2}$ are the main problem of the oxyfuel process, due to a large proportion of them dissolving into the liquid phase during liquefaction of the $\mathrm{CO}_{2}$ and possibly leading to problems with transport,

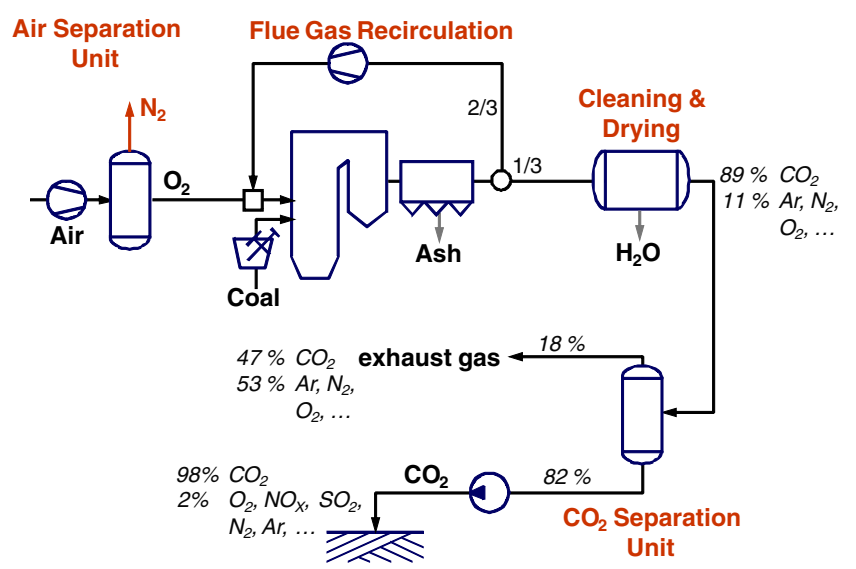

Fig. 1 Simplified schematic of the oxyfuel process. Conditions for example calculation: South African hard coal, leakage air proportion: $1 \%$ (referred to the flue gas mass flow at the outlet of the boiler), oxygen purity: 99.5 vol.\%, excess oxygen: $15 \%$. All percentages in $\mathrm{mol} \%$ 
particularly in the geological storage facility into which the $\mathrm{CO}_{2}$ is to be fed. Over and above this, these impurities require greater energy input during $\mathrm{CO}_{2}$ liquefaction. With the impurities assumed here and a gross power output of $600 \mathrm{MW}_{\text {el,gross }}$, the power requirement for $\mathrm{CO}_{2}$ liquefaction will be around $50 \mathrm{MW}_{\mathrm{el}}$. The lower the level of impurities, the lower the energy input required for liquefaction. In the case of oxygen purity of $99.5 \mathrm{vol} . \%$, the power requirement of the ASU is approx. $90 \mathrm{MW}_{\mathrm{el}}$ for a power station with

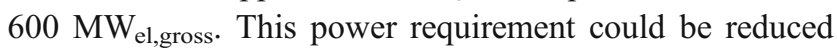
by implementing multi-column processes instead of the two-column process used to date-and an associated reduction in the oxygen purity in the air-separation unit to 95 vol.\% - to approx. $70 \mathrm{MW}_{\mathrm{el}}$ (Darde et al. 2009). However, the greater proportion of impurities then leads to an increase in the power requirement for $\mathrm{CO}_{2}$ liquefaction. Moreover, multi-column processes tend to be less flexible with regard to load changes.

As a result of the stated power requirements, the net unit efficiency of the 600-MW power station in this case will be reduced by approx. $11.5 \%$ points, when using the twocolumn process that produces 99.5 vol. $\%$ oxygen. The aim is to lower this efficiency drop to approx. $8 \%$ points, e.g. by implementing more efficient processes for air separation and reducing the oxygen purity and by further overall process integration.

In the first section, the flue gas recirculation requirements necessary to maintain similar heat duties in the various steam generator sections, excess oxygen requirements as well as radiative and convective heat-transfer issues are discussed. Based on experimental results, firing issues are covered in detail. The main focus is placed on the effect of the different atmosphere on the combustion process. Furthermore, pollutant reduction measures are

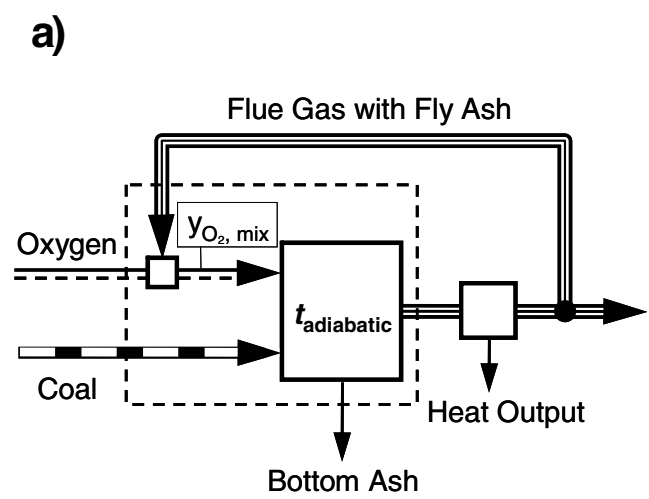

Fig. 2 a Schematic for the calculation of the required recirculation rate. Leakage air is not shown. b Recirculation requirement and oxygen concentration with simple mixing of the recycled flue gas with oxygen depending on the temperature of the recycled flue gas for South African hard coal and dried Lusatian lignite. Underlying investigated with a special emphasis on nitrogen oxides and sulphur components. Finally, results on the flue gas treatment including liquefaction and purification of the $\mathrm{CO}_{2}$ are presented.

\section{Heat balance and steam generation}

\section{Recirculation mass flow}

As already mentioned, cooled flue gas must be fed back into the furnace to prevent excessive combustion temperatures in the furnace. In terms of investment and due to technical restrictions, it is mandatory to retain the steam outlet temperature from the evaporator in the boiler at the same level as during the air-blown case. The furnace exit temperature cannot be altered, as it is defined by the coal quality. Accordingly, the amount of heat that has to be absorbed by the furnace walls needs to be the same as in the air-blown case. This is achieved if the adiabatic temperature in the furnace is approximately the same in the air and oxyfuel cases. The schematic behind this idea for the adiabatic combustion chamber and the resulting balance is shown in Fig. 2a).

Accordingly, the energy balance reads:

$$
\begin{aligned}
\dot{m}_{\text {flue }} h_{\text {flue }}= & \dot{m}_{\mathrm{O} 2} h_{\mathrm{O} 2}+\dot{m}_{\text {lair }} h_{\text {lair }}+\dot{m}_{\mathrm{C}}\left(h_{\mathrm{C}}+N C V\right) \\
& +\dot{m}_{\text {rec }} h_{\text {rec }}-\left(\dot{m}_{\text {fash }} h_{\text {fash }}+\dot{m}_{\text {bash }} h_{\text {bash }}\right)
\end{aligned}
$$

Here, $\dot{m}_{\text {flue }}, \dot{m}_{\mathrm{O} 2}, \dot{m}_{\text {lair }}, \dot{m}_{\mathrm{c}}, \dot{m}_{\text {rec }}, \dot{m}_{\text {fash }}$ and $\dot{m}_{\text {bash }}$ are the mass flows of flue gas, oxygen, leakage air, fuel, recirculation gas, fly ash, and bottom ash, respectively while $h_{\text {flue }}, h_{\mathrm{O} 2}, h_{\text {lair }}, h_{\mathrm{c}}, h_{\text {rec }}, h_{\text {fash }}$ and $h_{\text {bash }}$ are the corresponding enthalpies. The acronym NCV is the net

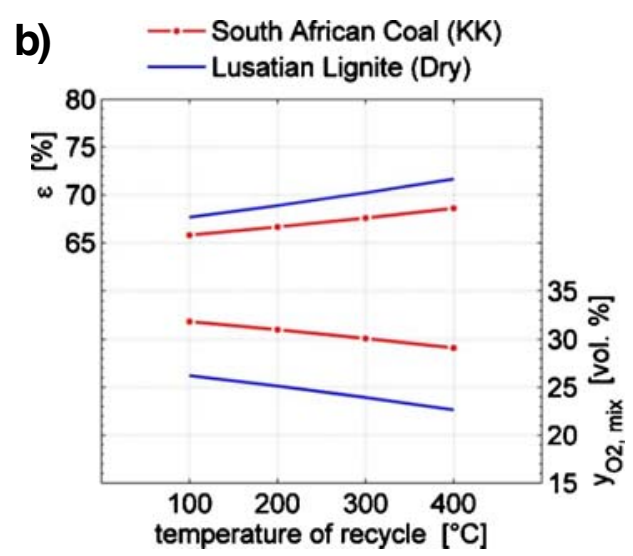

conditions: air temperature of the reference process, $320^{\circ} \mathrm{C}$; temperature of the oxygen, $180^{\circ} \mathrm{C}$; temperature of the coal, $40^{\circ} \mathrm{C}$; excess oxygen, $15 \%$; oxygen purity, 99.5 vol. $\%$; leakage air proportion, $1 \%$ referred to the total flue gas mass flow inside the boiler 
calorific value of the fuel. The flue gas mass flow results from the mass balance as follows:

$\dot{m}_{\text {flue }}=\dot{m}_{\mathrm{C}}+\dot{m}_{\mathrm{O} 2}+\dot{m}_{\text {lair }}+\dot{m}_{\mathrm{rec}}-\dot{m}_{\mathrm{fash}}-\dot{m}_{\mathrm{bash}}$

If the recirculation mass flow is now expressed by the following relationship:

$\dot{m}_{\text {rec }}=\varepsilon \times \dot{m}_{\text {flue }}$

the target recirculation rate $\varepsilon$ is obtained:

$\varepsilon=\frac{X-h_{\text {flue }}}{X-h_{\text {rec }}}$

where,

$X=\frac{\dot{m}_{\mathrm{O} 2} h_{\mathrm{O} 2}+\dot{m}_{\text {lair }} h_{\text {lair }}+\dot{m}_{\mathrm{C}}\left(h_{\mathrm{C}}+N C V\right)-\dot{m}_{\text {fash }} h_{\text {fash }}-\dot{m}_{\text {bash }} h_{\text {bash }}}{\dot{m}_{\mathrm{C}}+\dot{m}_{\mathrm{O} 2}+\dot{m}_{\text {lair }}-\dot{m}_{\text {fash }}-\dot{m}_{\text {bash }}}$

The direct calculation of the recirculation rate in accordance with Eq. 4 is only possible if the fresh oxygen mass flow, $\dot{m}_{\mathrm{O} 2}$, which is fed from the air-separation unit, is known. However, as a result of the residual oxygen content in the flue gas, the amount of fresh oxygen depends in turn on the recirculation mass flow. This will be discussed in more detail later.

Figure $2 \mathrm{~b}$ shows the recirculation rate for two coals in the temperature range of the recycled flue gas from 100 to $400^{\circ} \mathrm{C}$, calculated with equation (4). The examined hard coal is a typical representative of coals used in Europe; its composition is shown in Table 1. In accordance with Fig. 2b, for example, the recirculation requirement for the South African hard coal rises from approx. $65.8 \%$ at $100^{\circ} \mathrm{C}$ to $68.6 \%$ at $400^{\circ} \mathrm{C}$. The highest recirculation requirement is expected for dried lignite, due to a significantly lower furnace exit temperature (compared with hard coal), necessary due to the slagging behaviour of lignite. As the amount of heat that can be transferred in the furnace is limited due to material issues, the only possibility to attain lower furnace exit temperatures is lowering the adiabatic combustion temperature, which results in a higher recirculation requirement. Accordingly, at a recirculation temperature of $100^{\circ} \mathrm{C}$, the recirculation rate is already at $67.7 \%$ and at $400^{\circ} \mathrm{C}$ it is $71.7 \%$ for Lusatian lignite.

As will be explained later, the technically realistic temperature range for the flue gas recirculation lies between $200^{\circ} \mathrm{C}$ and $400^{\circ} \mathrm{C}$, which restricts the recirculation requirement in a hard-coal-fired power station to around $68 \%$, whilst in a dried lignite-fired power station to around $70 \%$.

\section{Recirculation temperature}

In today's steam generators, transfer of the flue gas heat to the water-steam cycle cools the flue gases down to temperatures between $350^{\circ} \mathrm{C}$ and $380^{\circ} \mathrm{C}$ before further cooling is carried out in the air pre-heater that is usually present. However, air pre-heaters of a regenerative type used in this process cannot be used in the oxyfuel process to preheat oxygen (or recirculation gas enriched with oxygen) as they always have a leakage of $5-10 \%$ from the oxygen carrier side to the flue gas side. This would additionally contaminate the flue gas with oxygen.

The technically relevant recirculation temperature is determined essentially by the following general conditions (Kather et al. 2007):

\section{Dimensions of the recirculation duct}

The recirculation temperature has a major influence on the dimensions of the recirculation ducts to be installed. For a bituminous coal-fired boiler with a firing rate of approx. $1200 \mathrm{MW}$, according the reference power plant North Rhine-Westphalia (RPP NRW, a technical and economical study on an advanced PF-fired steam power plant finalised in 2004 (Concept Study Reference Power Plant North Rhine-Westphalia (RPP NRW) (2004). Published by VGB PowerTech e.V., Essen, Germany)) analysed by the authors, a recirculation temperature of $300^{\circ} \mathrm{C}$ would result in an operating volume flow of approx. $400 \mathrm{~m}^{3} / \mathrm{s}$, requiring duct cross-sections of approx. $40 \mathrm{~m}^{2}$. This dimension, in the same order of magnitude as the RPP NRW analysed results, is an approximation based on the size of the flue gas duct cross-section downstream of the air pre-heater of the RPP NRW, which has a cross-section of $56.17 \mathrm{~m}^{2}$ for an operating volume flow of $563 \mathrm{~m}^{3} / \mathrm{s}$.

\section{Recirculation fan}

With regard to the design of the recirculation fan there is a choice between axial-flow fans or radial-flow fans. Axialflow fans feature isentropic efficiencies of $90 \%$, but can only be deployed up to temperatures of around $190^{\circ} \mathrm{C}$. This is due, above all, to the mechanical and hydraulic

Table 1 Coals used for the calculation of the adiabatic flame temperature and the recirculation requirement

\begin{tabular}{|c|c|c|c|c|c|c|c|c|}
\hline & $\begin{array}{l}\mathrm{NCV} \\
{[\mathrm{MJ} / \mathrm{kg}, \text { raw }]}\end{array}$ & $\begin{array}{l}\text { Water } \\
{[\%, \text { raw }]}\end{array}$ & $\begin{array}{l}\text { Ash } \\
{[\%, \mathrm{~d}]}\end{array}$ & $\begin{array}{l}\mathrm{C} \\
{[\%, \mathrm{daf}]}\end{array}$ & $\begin{array}{l}\mathrm{H} \\
{[\%, \mathrm{daf}]}\end{array}$ & $\begin{array}{l}\mathrm{N} \\
{[\%, \text { daf }]}\end{array}$ & $\begin{array}{l}\mathrm{S} \\
{[\%, \mathrm{daf}]}\end{array}$ & $\begin{array}{l}\mathrm{O} \\
{[\%, \mathrm{daf}]}\end{array}$ \\
\hline South African hard coal & 25.4 & 7.4 & 13.6 & 65.93 & 3.63 & 1.58 & 0.61 & 7.25 \\
\hline Lusatian dried lignite & 18.97 & 9.26 & 4.45 & 57.3 & 5.66 & 0.55 & 0.62 & 22.17 \\
\hline
\end{tabular}


components of the blade adjustment. If, on the other hand, no blade adjustment is used and a rigid-blade version is deployed instead, higher gas temperatures are possible, though this has a negative influence on the operating stability (pumping). As axial compressors require a higher rotational speed in comparison with radial compressors to generate the same pressure differential with the same volumetric flow, higher temperatures are a problem heredue to the strength of the blade materials. This means that, as a rule, radial-flow fans are used at higher gas temperatures. The blades on these fans are subject to lower mechanical loads on account of the design of the rotor. In most cases, this means that they are non-critical with regard to strength. In addition, the distance of the operating point from the pump limit is greater than in the case of axial-flow fans, which is an advantage with regard to load changes. The maximum deployment temperature for radial-flow fans of the size required here is specified by the manufacturers at around $450^{\circ} \mathrm{C}$. Higher temperatures would require expensive high-temperature steels. Moreover, costly and complicated start-up and shutdown devices have to be fitted to prevent sustained damage to the large rotor masses on heating up and cooling down.

Another major constraint in the case of axial-flow fans is the permitted dust load of the gas to be conveyed. This means that virtually complete dust removal from the recirculation gas is necessary upstream of an axial-flow fan. Also, as the non-recycled flue gas is to be subjected to dust removal, the electrostatic precipitator must be positioned upstream of the recirculation branch if an axial-flow fan is used. This way, the dust load can be limited to around 12 to $13 \mathrm{~g} / \mathrm{m}^{3}$ upstream of the electrostatic precipitator at $190^{\circ} \mathrm{C}\left(23 \mathrm{~g} / \mathrm{m}^{3} \mathrm{stp}\right.$, dry $)$ as well as to $0.01 \mathrm{~g} / \mathrm{m}^{3}\left(0.02 \mathrm{~g} / \mathrm{m}^{3}\right.$ stp, dry) in the recirculation duct, even if high-ash South African coal is used. The dust load at the comparable position (upstream of the air pre-heating at $370^{\circ} \mathrm{C}$ ) of the air-operated RPP NRW is only half that size (approx. $6 \mathrm{~g} /$ $\mathrm{m}^{3}$, corresponds to $15.5 \mathrm{~g} / \mathrm{m}^{3} \mathrm{stp}$, dry). A disadvantage of this configuration is that the electrostatic precipitator has to be dimensioned for the entire flue gas volume.

If the electrostatic precipitator is positioned downstream of the recirculation branch in the exhaust gas flow, the flue gas volume to be cleaned is approximately $66 \%$ lower. As the recirculation gas is fed back unfiltered to the furnace in this case, dust loads in the recirculation ducts of approx. $23 \mathrm{~g} / \mathrm{m}^{3}$ (at $350^{\circ} \mathrm{C}$, corresponds to $58 \mathrm{~g} / \mathrm{m}^{3}$ stp, dry) are reached. Thus, in comparison with the configuration described above, the recirculation fan is exposed to a 2,300-fold dust load, which means that only radial-flow fans with respective armouring and blade geometries can be deployed. However, the isentropic efficiency of such a fan is at a maximum $80 \%$. Isentropic efficiencies of radial-flow fans for dust-free media, on the other hand, achieve values nowadays that almost come up to those of axial-flow fans. Regarding the dust load in the steam generator, which is around 2.5-times higher as compared to the air-operated case, an appropriate design with respect to gas velocities should facilitate boiler operation that is not subject to excessive wear.

As the size of the recirculation fan is comparable to that of the induced-draught fan of the RPP NRW, a recirculation temperature that is as low as possible is, above all, beneficial with regard to the fan's power requirement.

\section{Fuel drying}

In conventional hard-coal power stations, fuel drying is carried out using $250-300^{\circ} \mathrm{C}$ hot air supplying the heat for drying. This is performed in the coal pulveriser where the temperature of the air decreases to about $65-110^{\circ} \mathrm{C}$. This mill air serves simultaneously as transport gas and, at the same time, provides a part of the oxygen for combustion. As air is not available in the oxyfuel process, mill drying can only be carried out with hot flue gas, e.g., with a portion of the recycled flue gas. The lack of oxygen in the transport gas is not a problem from the viewpoint of firing, since this can be compensated by an appropriate oxygen supply in the near-burner region. The use of cold flue gas significantly below $300^{\circ} \mathrm{C}$ would require an increased gas mass flow for adequate drying. This, however, could impair the conditions for a secure ignition (Pulverised Coal Oxycombustion Power Plants 2008).

\section{Electrostatic precipitator}

The operating temperature of electrostatic precipitators (ESP) nowadays lies at temperatures below $200^{\circ} \mathrm{C}$. Hightemperature ESPs are also in service in industrial applications, whereby their major drawback has to be attributed to the larger volume. Whether or not a higher temperature may impair the precipitation efficiency cannot be answered in advance; this depends on many factors like ash properties, sulphur content, and the $\mathrm{CO}_{2}$ concentration too. It is, for example, known from Japanese power plants burning a low-sulphur coal that a high-temperature arrangement of the ESP was beneficial with respect to precipitation performance (Forzatti 2001).

\section{Total rate of efficiency}

In the RPP NRW, the rise in the power station net efficiency to $45.9 \%$ was achieved by, among other things, raising the boiler feed water inlet temperature to $302^{\circ} \mathrm{C}$ by regenerative feed water pre-heating. In order to subsequently transfer the flue gas heat to the feed water, a certain temperature difference between flue gas and feed water is required. This is why from a technological point of view the flue gas or recirculation temperature cannot be 
significantly lower than $350^{\circ} \mathrm{C}$. Lowering the recirculation temperature is only possible when the boiler feed water inlet temperature is lowered as well, which would adversely affect the overall efficiency, or if a possibility could be found to transfer the flue gas heat to the water-steam cycle without impairing the regenerative feed water pre-heating. With regard to the total efficiency, however, the current state of knowledge indicates that lowering the recirculation temperature is not an advantage.

Under the given general conditions, it does not make sense to carry out the flue gas recirculation at unnecessarily high temperatures, especially when it is taken into account that there are limits here with regard to the recirculation fan and constraints with regard to the dimensions of both the electrostatic precipitator and the duct system. The cooling of the flue gases that can be achieved depends decisively on the possibility to integrate the flue gas heat in the overall process without decreasing the overall efficiency. Accordingly, high recirculation temperatures are generally beneficial with respect to the overall efficiency, even if the recirculation fan's power demand is higher. On the other hand, investment costs could favour lower recirculation temperatures, due to a smaller duct system. At the moment, the best recirculation temperature cannot be quantified, but it is currently expected that the relevant temperature range is at $200-400^{\circ} \mathrm{C}$.

\section{Excess oxygen with oxyfuel combustion}

One of the most important boundary conditions regarding a power station based on the oxyfuel process is the excess oxygen to be used. In the case of conventional air-operated coal-fired power stations the excess oxygen is identical to the excess air that is set for the most modern systems with air ratios, $\lambda$, down to 1.15 , i.e. $15 \%$ excess oxygen. The reason for this relatively high value, as compared to gasfiring, is that the coal mass flow to be distributed from one mill to several burners cannot be evenly distributed among these burners. This means that a burner that is temporarily delivered with too much coal would be operated with an air ratio that is too low as the flux of the pulverised coal cannot be measured with the same accuracy as the air flux. Accordingly, burnout problems arise and-which is more severe - the risk of corrosion on the furnace walls increases dramatically. In the case of natural-gas-fired or light-oilfired furnaces, where the distribution of the fuel to the burners is significantly more uniform, excess air rates of less than $5 \%$ can be operated safely. In the development of the oxyfuel process for coal-fired furnaces, however, the coal distribution problem means that an excess oxygen of $15 \%$ must be assumed in the first place as this has proven to be the smallest excess rate that can be securely operated in coal furnaces. Also, the case is examined if it was possible to reduce the excess oxygen to $10 \%$ by improving the uniformity of the coal dust distribution.

In the case of the oxyfuel process, the correct definition of the excess oxygen is of particular significance as different definitions are possible in principle. Before being merged with the fuel, the oxygen is mixed with the recycled flue gas. This can either take place in a single mixing stage or at various positions with different mixing ratios, which does not affect the overall excess oxygen. Basically, the excess oxygen is defined as surplus in oxygen in relation to the stoichiometric oxygen requirement $\underline{m}_{\mathrm{O} 2 \text {,stoic }}$. As both the oxygen originating from the air-separation unit and the residual oxygen of the recycled flue gas are fed to the furnace, the oxygen mass flow actually fed into the furnace is greater than that delivered by the air-separation unit. Accordingly, the global excess oxygen, $\mathrm{O}_{2, \mathrm{ex}}$, reads:

$\lambda-1=O_{2, \mathrm{ex}}=\frac{\dot{m}_{\mathrm{O} 2, \mathrm{ASU}}+\dot{m}_{\mathrm{O} 2, \mathrm{LA}}+x_{\mathrm{O} 2, \mathrm{res}} \times \dot{m}_{\mathrm{R}}}{\dot{m}_{\mathrm{O} 2, \text { stoic }}}-1$

Here, $\dot{m}_{\mathrm{O} 2 \text {,ASU }}$ refers to the oxygen mass flow delivered by the air-separation unit, $\dot{m}_{\mathrm{O} 2 \text {, LA }}$ the oxygen mass flow that enters with the leakage air, $x_{\mathrm{O} 2 \text {,res }}$ the residual mass fraction of oxygen in the recycled flue gas, $\dot{m}_{\mathrm{R}}$ the recirculation mass flow, and $\dot{m}_{\mathrm{O} 2 \text {,stoic }}$ the stoichiometric oxygen requirement of the fuel.

Considering the simplest case where the recycled flue gas is completely mixed with the oxygen at a single position (see Fig. 2a) it can be concluded that the oxygen concentration of the mixture cannot be chosen arbitrarily. Rather, it depends on the temperature of the flue gas recirculation, on the required excess oxygen, and on the coal used. Fig. 2b shows the dependency of the oxygen concentration on the temperature of the recirculation. A theoretical oxygen content for South African hard coal in the mixed atmosphere of 31-29 vol.\% reached the technically realistic temperature range of $200-400^{\circ} \mathrm{C}$ (see Fig. 2b). In the case of dried lignite, the corresponding oxygen concentration in the mixed atmosphere is in the range of 25-23 vol.\%. Thus, the oxygen content of the mixed atmosphere is significantly higher than that of air. Furthermore, it can be observed that for given oxygen excess, the oxygen concentration in the mixture is decreasing with an increasing recirculation rate. Adjusting arbitrary oxygen concentrations in the combustion atmosphere is, hence, only possible locally by distributing the oxygen asymmetrically to separate branches of the recycle. A staging of oxygen concentration of this kind will already be existent if recycled flue gases are fed to the mills without oxygen enrichment in order to perform the mill-internal coal drying at elevated temperatures. The oxygen concen- 
tration in the remaining mixture of flue gas and oxygen could then be as high as 40 vol.\%.

It is known for the combustion of solid fuels that the air to fuel ratio and, likewise, the excess oxygen cannot be reliably determined measuring air and fuel mass flows. Besides the difficulties in measuring the fuel mass flow, this is also due to the non-measurable leakage air. Therefore, the excess oxygen $\left(\mathrm{O}_{2 \mathrm{ex}}\right)$ is determined by measuring the residual oxygen content in the flue gas, which depends directly on the carrier's gas oxygen content, as well as on the fuel's stoichiometric oxygen requirement. If, on the other hand, there is flue gas recirculation, the residual oxygen content additionally depends on the recirculation rate. The theoretical oxygen excess, $\mathrm{O}_{2 \mathrm{ex}}$, can be calculated by the following expression:

$\mathrm{O}_{2, e x}=\frac{X_{\mathrm{O} 2, \text { flue }}}{O_{2, \text { min }}}\left(\frac{X_{\mathrm{O} 2, \mathrm{oc}}\left(1-\gamma_{\mathrm{ash}}\right)+O_{2, \text { stoic }}-X_{\mathrm{O} 2 \text { fflue }} \mu_{\mathrm{w}}(1-\varepsilon)}{(1-\varepsilon)\left(X_{\mathrm{O} 2, \mathrm{oc}}-X_{\mathrm{O} 2, \text { flue }}\right)+\alpha\left(X_{\mathrm{O} 2, \mathrm{air}}-X_{\mathrm{O} 2, \mathrm{oc}}\right)}-\mu_{w}\right)$

where,

$\mu_{\mathrm{w}}=\frac{8,9366 \gamma_{\mathrm{H}}+\gamma_{\mathrm{w}}}{1-\varepsilon}$

Here, $x_{\mathrm{O} 2 \text {,flue, }} x_{\mathrm{O} 2, \mathrm{oc}}$ and $x_{\mathrm{O} 2 \text {,air }}$ are the mass fractions of oxygen in the recycled dry flue gas, in the oxygen carrier, and in air, respectively, $\mathrm{O}_{2 \text {,stoic }}$ is the fuels stoichiometric oxygen requirement and $\gamma_{\mathrm{ash}}, \gamma_{\mathrm{H}}$ and $\gamma_{\mathrm{w}}$ are the mass fractions of the fuel's ash, hydrogen and water, respectively, $\varepsilon$ denotes the recirculation rate according to Eq. 3. The variable $\alpha$ refers to the leakage air flow related to the total flue gas mass flow (see Eq. 9).

According to the formula dependency of the excess oxygen shown by Eq. (7), the residual oxygen content is as high as 4.9 vol.\% (stp, dry) for a recirculation rate of $67 \%$ when burning South African hard coal with an excess oxygen of $15 \%$. Consequently, the residual oxygen content in the flue gas is significantly higher than in the air-operated case where it amounts up to approx. 2.8 vol.\% (stp, dry) under comparable boundary conditions. As already mentioned above, the oxygen fraction in the flue gas is unfavourable with respect to the subsequent $\mathrm{CO}_{2}$ liquefaction.

The strong dependency of the excess oxygen on the recirculation rate is a result of the fact that the overall oxygen excess cannot be determined by merely measuring the residual oxygen content. Rather, additional measurements are necessary, such as a sufficiently exact volumeflow measurement of the recirculation gas.

Steam generation and heat transfer

The steam generator of the oxyfuel process will not differ significantly from an air-operated steam generator, as is the case for the flue gas cleaning systems or as the very high flue gas recirculation might initially indicate.

One question of particular interest for the oxyfuel case is the size of the steam generator, as the flue gas composition changes significantly. With the above assumptions that the adiabatic temperature is to remain similar in air and oxyfiring, the flue gas mass flow in the boiler will be approx. $12 \%$ to $15 \%$ smaller than in a comparable airoperated boiler, which is caused by the higher specific heat capacity of the flue gas. In addition, as the flue gas density is approx. $22 \%$ higher, the cross-sectional area of the steam generator would be approx. $30 \%$ smaller when maintaining the same mean gas velocity at the entrance of the convective heat exchangers.

The steam generator's height is, to a great extent, determined by the required heating surface of the furnace. As the furnace exit temperature is governed by the ashfusion temperature, remaining unchanged in the oxyfuel process, the amount of heat to be transferred in the furnace will be the same as in the air-operated case. Consequently, the dimensions of the heating surface are only determined by the overall heat-transfer coefficient.

Heat transfer in the furnace is almost exclusively due to radiation of the gaseous components carbon dioxide and water vapour as well as particles and soot. As the oxyfuel flue gas consists almost entirely of these components, it is tempting to expect that the radiative heat transfer will increase accordingly. This is true for pure gas radiation if neither particles nor soot are present. Using wellestablished calculation models (Blokh 1987) reveals, however, that the emission of the gas-particle-soot mixture in the furnace is close to the black-body radiation already in the air-fired case, which is due to the predominant radiation of glowing ash particles and burning coke. The predominant influence of particle radiation has also been observed by other authors (Andersson et al. 2008). Thus, it is not reasonable to assume that higher $\mathrm{CO}_{2}$ and vapour concentrations in coal furnaces would further promote the radiate heat transfer inside the furnace, which is why the required heating surface will not change significantly. Therefore, the furnace height would be approx. $20 \%$ higher in order to compensate for the reduced cross-sectional area.

Upon reaching the convective heat exchanger section, the predominance of the particle radiation constantly vanishes. So, compared to the air-fired case, the heattransfer coefficient is increasing according to the changed gas composition. There is, however, still some uncertainty about the extent of this increase.

The deposit formation on the heat exchanger surfaces leads to further intensification of the uncertainties in the heat-transfer characteristics in the same way as in all systems fired with solid fuels containing ash. This means that the behaviour of the fly ash, due to the changed gas 
composition, is of interest. These deposits formed by the fly ash will impair the heat transfer and may promote corrosion, both of which will finally limit the boiler's operating time. It should also be taken into account that fly ash, at least in the case of hard-coal power stations under certain conditions, is a reusable power station by-product.

To assess the deposit behaviour, a ceramic, uncooled sample carrier was used for this on a $500-\mathrm{kW}$ test facility fired under oxyfuel conditions. This was exposed to the dust-loaded flue gases at a temperature of approx. $750^{\circ} \mathrm{C}$. Here, of interest was the formation of carbonates due to the high $\mathrm{CO}_{2}$ partial pressure in the oxyfuel operation. Initial results of deposit analysis after short-term exposure to the flue gases indicated an increased carbonate formation. Further results are expected from the exposure of sample carriers in the corresponding gas atmospheres as well as from comparative analyses in the case of air combustion. The extent to which the carbonate formation that was determined influences the heat-transfer resistance of the heating surface deposits and the cleanability with heating surface-cleaning devices shall be the subject of further investigations.

\section{Experimental examination of the combustion}

An elementary combustion calculation shows additional characteristic properties of the process. Table 2 shows the results of a stoichiometric combustion calculation with air and/or with pure oxygen for Klein Kopje coal in accordance to Table 3.

The reduction in the specific flue gas volume by a factor of 4 to 5 corresponds to the lack of the air-nitrogen proportion. This also means that the $\mathrm{CO}_{2}$ concentration is accordingly high, though in reality the above-mentioned impurities of the oxygen provided by the ASU, the leakage air, as well as the required excess oxygen will lead to values of around 89 vol.\%.

Accordingly, the concentration of specific components like ash, $\mathrm{SO}_{2}$, or water vapour will increase. This applies only if there has been no selective removal of the corresponding components upstream of the recirculation branch, for example, by means of a dust removal or desulphurisation facility. The concentration increase is also independent of the recirculation rate $\varepsilon$. This concentration increase needs to be considered as far as water vapour, but also as corrosive gas components like $\mathrm{HCl}$ or $\mathrm{SO}_{3}$ are concerned. However, in the case the concentration increase of a component could be avoided or at least limited, the emitted mass flow of this component will be lowered according to the lower gas flows (Mieske and Kather 2007). This especially applies to $\mathrm{NO}_{X}$ as discussed later.

With regard to the combustion process, the following questions now arise:

- Do the combustion characteristics of coal in a $\mathrm{CO}_{2}-$ $\mathrm{H}_{2} \mathrm{O}-\mathrm{O}_{2}$ atmosphere differ from the combustion characteristics in air?

- Can harmful substances such as $\mathrm{NO}_{X}$ and $\mathrm{SO}_{2}$ be influenced by firing measures?

- Do the fouling and slagging characteristics change? Are there effects on the cleaning characteristics of heating surface deposits?

- Heating surfaces and other components can be subjected to corrosion due to the complex combined effects of deposits and the gas atmosphere. Are changes to be expected here?

\section{Test facilities used}

The results presented in this section were mainly obtained in an electrically heated laboratory reactor $\left(20 \mathrm{~kW}_{\mathrm{th}}\right)$ and in a semi-technical test facility $\left(500 \mathrm{~kW}_{\mathrm{th}}\right)$. Both systems have been used successfully for many years to characterise fuel and research operating problems in hard-coal and lignitefired furnaces. Both plants were lately modified for oxyfuel conditions. Comprehensive tests under oxyfuel and-for reference purposes - air conditions were carried out on both systems with the South African hard coal Klein Kopje (abbreviation KK) and Lusatian dried lignite (abbreviation LA). The properties of these two coals are given in Table 3. In addition, experience has already been acquired with other national and international coal qualities.

A mixture of oxygen and $\mathrm{CO}_{2}$ as oxidiser is fed to the $20 \mathrm{~kW}$ laboratory reactor. This system has no flue gas recirculation. The recirculation rate is simulated via the
Table 2 Results of the elementary combustion calculation for the air and oxyfuel case (Klein Kopje coal)

\begin{tabular}{llcc}
\hline & & Air & Oxyfuel \\
\hline Specific dry volumetric flow of flue gas & {$\left[\mathrm{m}^{3} \mathrm{stp} / \mathrm{kg}\right]$} & 6.351 & 1.220 \\
Ash content in flue gas & {$\left[\mathrm{g} / \mathrm{m}^{3} \mathrm{stp}\right]$} & 27.15 & 112.53 \\
$\mathrm{CO}_{2}$ content in dry flue gas & {$[\mathrm{vol} \%]$} & 19.02 & 98.84 \\
$\mathrm{SO}_{2}$ content in dry flue gas & {$[\mathrm{ppm}]$} & 601 & 3130 \\
Water content in flue gas & {$[\mathrm{vol} \%]$} & 7.26 & 26.16 \\
\hline
\end{tabular}


Table 3 Fuel parameters of the coals used in the test facilities

\begin{tabular}{|c|c|c|c|c|c|c|c|c|c|}
\hline & $\begin{array}{l}\mathrm{NCV} \\
{[\mathrm{kJ} / \mathrm{kg} \text {, raw }]}\end{array}$ & $\begin{array}{l}\text { Water } \\
{[\%, \text { raw }]}\end{array}$ & $\begin{array}{l}\text { Ash } \\
{[\%, d]}\end{array}$ & $\begin{array}{l}\text { Volatile } \\
{[\%, \text { daf }]}\end{array}$ & $\begin{array}{l}\mathrm{C} \\
{[\%, \mathrm{daf}]}\end{array}$ & $\begin{array}{l}\mathrm{H} \\
{[\%, \mathrm{daf}]}\end{array}$ & $\begin{array}{l}\mathrm{N} \\
{[\%, \mathrm{daf}]}\end{array}$ & $\begin{array}{l}\mathrm{S} \\
{[\%, \mathrm{daf}]}\end{array}$ & $\begin{array}{l}\mathrm{O} \\
{[\%, \mathrm{daf}]}\end{array}$ \\
\hline Klein Kopje (KK) & 24,932 & 3.60 & 19.29 & 27.76 & 83.63 & 4.48 & 1.66 & 0.72 & 9.51 \\
\hline Lusatian lignite (LA) & 21,412 & 10.20 & 5.46 & 57.36 & 66.69 & 5.25 & 0.65 & 0.85 & 26.56 \\
\hline
\end{tabular}

different proportions of $\mathrm{O}_{2} / \mathrm{CO}_{2}$ in the oxidiser. Furthermore, gas components such as $\mathrm{NO}$ or $\mathrm{SO}_{2}$ are added specifically to the oxidiser to simulate the conditions of a flue gas recirculation as precisely as possible. In this way, the test rig provides the possibility to examine the two oxyfuel-specific effects - changed composition of the oxygen carrier and increased oxygen concentration prior to combustion-separately. The emission rate relates the proportion of pollutants to the introduced fuel; the reduction rate refers to the proportion of pollutants that are already added upstream of the furnace and either inhibit the original conversion or react to form other products.

The $500-\mathrm{kW}$ test facility, on the other hand, is equipped with a recirculation, whereby dust-cleaned flue gas is recycled. The recycled flue gas is preheated via a flue-gas-heated heat exchanger and routed to the burner after addition of the oxygen. The pulverised and dried fuel is fed to the burner pneumatically using $\mathrm{CO}_{2}$ as the transport gas. No further description of the test facilities will be provided here, more information on this topic can be found in Maier et al. (2007).
Combustion characteristics with oxyfuel combustion

In order to be able to make initial statements regarding the combustion characteristics, axial gas concentration profiles were measured on the $20-\mathrm{kW}$ system. In addition to the conventional air-operated method, two test settings with different $\mathrm{O}_{2} / \mathrm{CO}_{2}$ ratios of the oxidiser for oxyfuel were used. For the latter, the indication OF21 or OF27 is used, designating an $\mathrm{O}_{2} / \mathrm{CO}_{2}$ ratio of $21 / 79$ or $27 / 73$ vol. $\%$. The system was operated in such a way that constant gas flows occur in the furnace. This results in a higher thermal input in the OF27 case than in the case of air combustion or the OF21 case. This has the benefit that axial concentration profiles always correspond to a uniform course of residence time. The total excess oxygen was a uniform $15 \%$.

Figure 3a shows the concentration profiles determined in this way for $\mathrm{O}_{2}$ and $\mathrm{CO}$ with the combustion of Klein Kopje coal. The comparison of the $\mathrm{O}_{2}$ profiles shows a similar course for the air and the OF27 case, whereas the combustion in the OF21 case is delayed.
Fig. 3 Combustion characteristics. a Courses of $\mathrm{O}_{2}$ and $\mathrm{CO}$ concentration along the burner axis (Klein Kopje coal). b Carbon and nitrogen content of the char composition along the burner axis

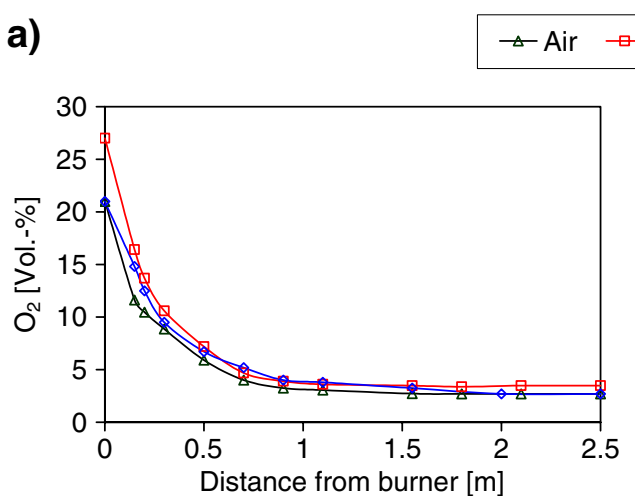

OF27 $\rightarrow$ OF21

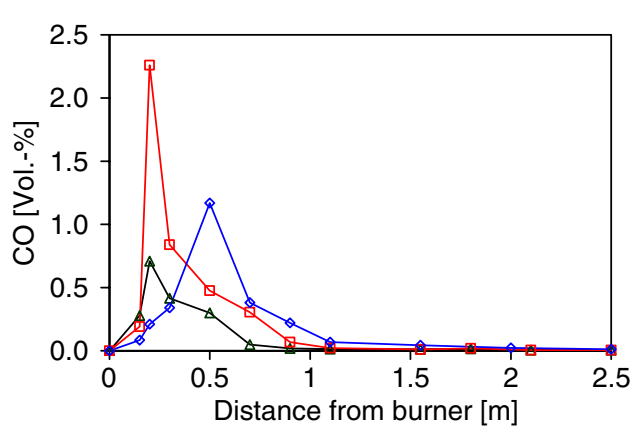

b)

$\rightarrow$ Air, KK $-₫-$ OF27, KK $\rightarrow$ Air, LA $-\rightarrow-$ OF27, LA
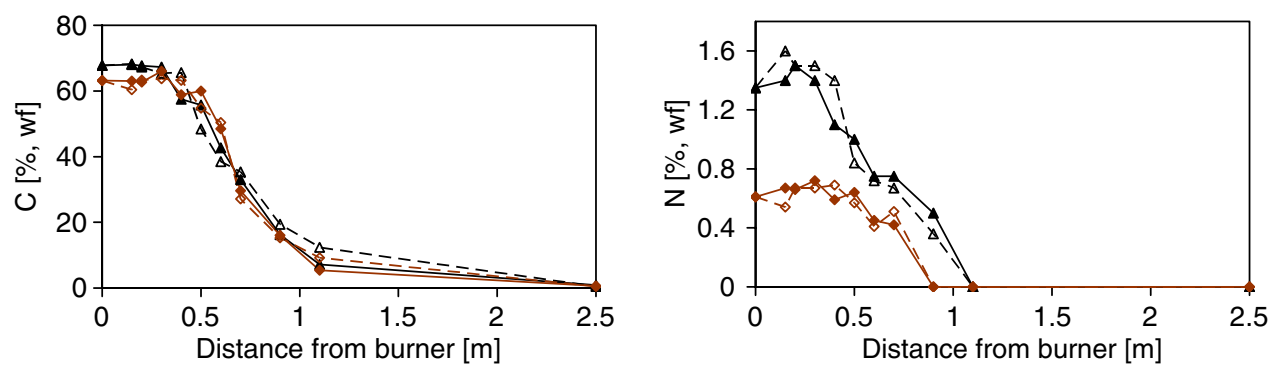
A likely explanation is the higher thermal capacity of $\mathrm{CO}_{2}$ in comparison with $\mathrm{N}_{2}$. This is compensated by the higher oxygen concentration in the OF27 case and, accordingly, leads to a similar degree of fuel oxidation. This is also clearly indicated by the measured $\mathrm{CO}$ profiles. The maximum of the $\mathrm{CO}$ concentration is significantly shifted in the OF21 case, whereas in the air and in the OF27 case, the $\mathrm{CO}$ maximum occurs at the same position. However, the levels of $\mathrm{CO}$ concentration are different.

This can be explained with the Boudouard reaction $\mathrm{C}+$ $\mathrm{CO}_{2} \leftrightarrow 2 \mathrm{CO}$ and the water gas reaction $\mathrm{CO}+\mathrm{H}_{2} \mathrm{O} \leftrightarrow \mathrm{CO}_{2}$ $+\mathrm{H}_{2}$, as a higher $\mathrm{CO}_{2}$ concentration leads to higher $\mathrm{CO}$ concentrations (Al-Makhadmeh et al. 2009). The rise in $\mathrm{CO}$ concentration that was observed was also determined with other fuels and is a characteristic of oxyfuel combustion. This must be taken into account, particularly, for the evaluation of flue gas atmospheres with regard to furnace wall corrosion.

Further insight into the combustion progress is provided by the analysis of the char that was sampled at different axial positions in the reactor. Figure $3 \mathrm{~b}$ shows the corresponding courses of the carbon and nitrogen content in the char. The two cases of combustion with air and OF27 are compared for the two fuels Klein Kopje (KK) and Lusatian dried lignite (LA). Essentially, a similar burn-off course and a similar burnout can be seen if the case of air is compared with the oxyfuel OF27 case for each fuel.

Nitrogen oxide formation and reduction

Previous results were achieved with total oxygen supply via the burner, i.e. no staging was applied. Contrary, initial attempts to assess the NO formation and reduction by means of a staged sequence of combustion-as often practised for the case of air-were carried out with the $20 \mathrm{~kW}$ reactor. Alongside the total excess air or excess oxygen, two other parameters are required for characterisation: the stoichiometry in the area of the burner (the burner stoichiometry is the amount of air or oxygen supplied via the burner related to the stoichiometric air or oxygen requirement of the fuel) and the residence time between the burner and burnout air and/or residual oxidiser addition (Kluger et al. 2001). For comparison with conventional air combustion, the oxyfuel OF27 case was used.

Even in the initial test results, as shown in Fig. 4a, familiar dependencies with regard to the residence time and burner stoichiometry became apparent for the $\mathrm{NO}_{X}$ emissions at the furnace outlet (due to the different specific volume flows, the $\mathrm{NO}_{X}$ values were related to the fuel heat input (NCV) that was introduced). The lower $\mathrm{NO}_{X}$ values in the oxyfuel case in comparison with the air case can be explained by the suppressed thermal NO formation due to the lack of nitrogen. On the basis of detailed profile measurements in the immediate vicinity of the burner, it was possible to show that the familiar NO precursor components $\mathrm{HCN}$ and, in the case of lignite also, $\mathrm{NH}_{3}$ are also detected in a $\mathrm{CO}_{2}$-rich oxyfuel atmosphere in the same way as with air combustion. Corresponding courses are summarised in Fig. 5, whereby again the air and the oxyfuel OF27 case were compared for the two fuels Klein Kopje and Lusatian dried lignite.

Due to the fact that under the specific conditions of the $20-\mathrm{kW}$ reactor similar NO values for oxyfuel and air combustion were determined, the question arises to which extent NO present in the oxidiser is reduced in the furnace. In the real oxyfuel system, NO will always be present in the oxidiser via the flue gas recirculation as long there is no NO reduction facility in the flue gas between the furnace and the recirculation branch.

To examine this, other tests were carried out with an additional quantity of $\mathrm{NO}$ in the $\mathrm{O}_{2} / \mathrm{CO}_{2}$ mixture (Dhungel et al. 2007). Some NO was added optionally to the oxidiser at the burner and to the oxidiser that was later added for complete burnout. The designations BR (burner) and BO (burn out) in Fig. 4b indicate these two cases.

The tests were carried out with an unstaged flame and a flame with gas-staging with burner stoichiometries of 0.75 to 0.95 and a total stoichiometry of 1.15 that remained constant in all tests. The residence time in the primary zone was $3 \mathrm{~s}$. The main insight acquired from these tests is summarised in Fig. 4b. The designation KK or LA once
Fig. $4 \mathrm{NO}_{X}$ chemistry. a $\mathrm{NO}_{X}$ emissions depending on the burner stoichiometry and residence time (Klein Kopje coal, total stoichiometry, 1.15) (Dhungel et al. 2007). b Reduction rate of recycled $\mathrm{NO}$ with variation of the burner stoichiometry (total stoichiometry, 1.15 ; residence time in the primary zone, $3 \mathrm{~s}$; Dhungel et al. 2007) a)

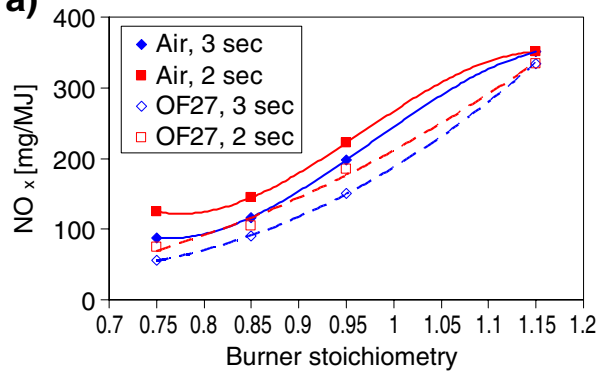

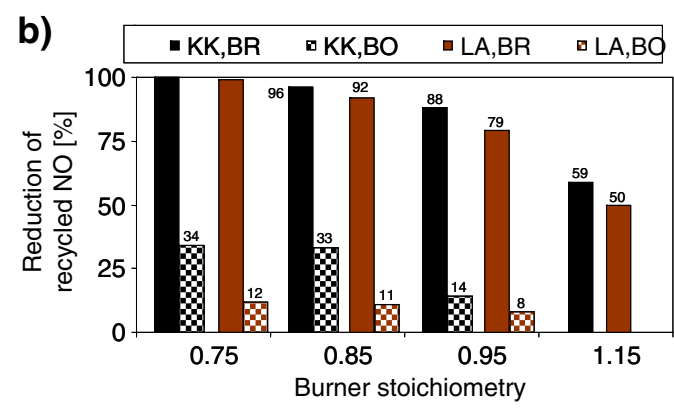


Fig. 5 Characteristics of gas concentration along the burner axis (total stoichiometry, 1.15; burner stoichiometry, 0.75 ; residence time in the primary zone, 3 s; Dhungel et al. 2007)

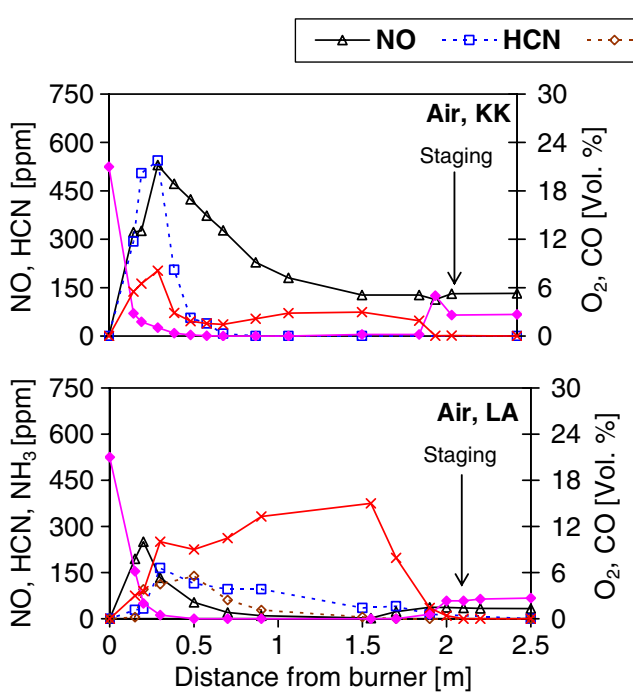

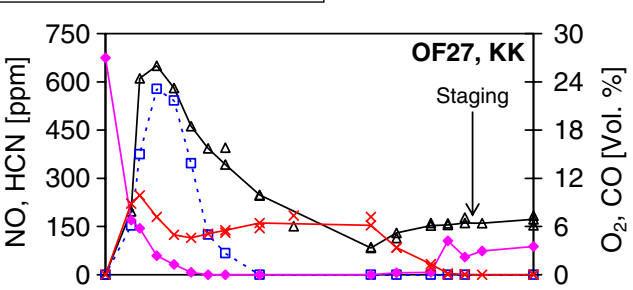

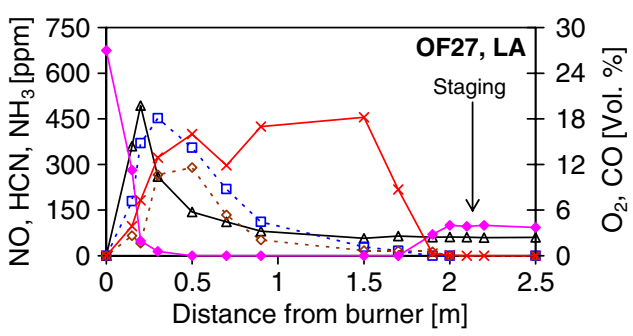

again indicate the coals Klein Kopje and Lusatian dried lignite. The reduction rates $\beta_{\mathrm{NO}}$ displayed in Fig. $4 \mathrm{~b}$ are defined as follows:

$\beta_{\mathrm{NO}}=1-\frac{y_{\mathrm{NO}, \mathrm{wi}}-y_{\mathrm{NO}, \mathrm{wo}}}{y_{\mathrm{NO}, \mathrm{i}} \frac{\dot{V}_{\mathrm{i}}}{\dot{V}_{\mathrm{Fg}}}}$

Here, $y_{\mathrm{NO}, \mathrm{w}} \mathrm{i}$ and $y_{\mathrm{NO}, \mathrm{wo}} \mathrm{i}$ are the measured NO concentrations with and without injection of additional $\mathrm{NO}$ in the oxidiser, $y_{\mathrm{NO}, \mathrm{i}}$ is the NO concentration in the oxidiser achieved by injection, $\dot{V}_{\mathrm{i}}$ is the volume-flow rate (stp) of the oxidiser subject to NO injection, and $\dot{V}_{\mathrm{Fg}}$ is the volume flow rate (stp) of the flue gas after full oxidation. The reduction rate represents the share of the NO introduced into the furnace via the recycle that is reduced, hence, not contributing to the final NO formation.

With a burner stoichiometry of 0.75 , the entire recycled $\mathrm{NO}$ that is fed via the burner is converted into $\mathrm{N}_{2}$, i.e. the reduction is $100 \%$. With an increase in the burner stoichiometry, the reduction rate drops to $50-60 \%$ using the unstaged oxyfuel method. In other tests, NO was fed exclusively via the staging gas injection. Significantly lower reduction rates and strong dependencies on the coal used were observed here. The main reason for these differences may well be that hydrocarbon radicals as well as NO precursor components are no longer available for the reduction reactions at the point where the burnout gas is added.

As a general principle, the results underline the fact that the developed primary measures for NO reduction in coalfired power stations can also be applied successfully under oxyfuel conditions. However, it has to be taken into account that a reduction of the recycled NO loads only takes place if the recycled gases pass substoichiometric zones that have the relevant components for NO reduction.
With regard to the risk of corrosion due to the higher concentrations of certain gas components, the staging is more likely to be set relatively moderate on the real oxyfuel system. According to the selected staging, recycled flue gas - and thus NO - will also have to be added via burnout gas, as solely the theoretically possible oxygen addition is unlikely to achieve adequate mixing. Taking the mentioned constraints and the achieved results into account, the total reduction of recycled $\mathrm{NO}$ on the real oxyfuel system is likely to reach $60 \%$ to $80 \%$. This means that a certain increase in the concentration of NO cannot be avoided and slightly higher NO concentrations are to be expected. However, this is overcompensated by the reduction of the flue gas volume (cf. Table 2) and the NO mass flows fed to the flue-gas cleaning will fall significantly.

\section{Characteristics of sulphur}

The following section describes specific parameter examinations of the characteristics of sulphur components. The discourse at the beginning of this section (see Table 2) has priority if it is assumed that the sulphur components of the fuel are fully converted into $\mathrm{SO}_{2}$. Depending on the fuel, however, sulphur is also captured in the ash in the course of flue gas cooling. If dust including captured sulphur is removed from the recycled flue gases, this sulphur sink reduces the increase of the concentration of $\mathrm{SO}_{2}$ accordingly. For these fuel-dependent sulphur-capturing characteristics, numerous tests indicated there were no significant differences between conventional air combustion and oxyfuel combustion (see Maier et al. 2007). The sulphur selfcapturing in the oxyfuel process will run in a manner comparable to that in conventional air combustion.

The chemical speciation of sulphur during combustion is of particular interest, especially if staging is used to reduce 
the nitrogen oxides. Whereas in air combustion, sulphur is only added via the fuel, in the oxyfuel process, the $\mathrm{SO}_{2}$ is another sulphur component in the recycled flue gas. This relationship was investigated using the $20-\mathrm{kW}$ test facility. Tests were carried out on staged flames with a total stoichiometry of 1.15 and a burner stoichiometry of 0.75 . The gas residence time in the substoichiometric zone was 3 s. To simulate the recycled $\mathrm{SO}_{2}$ concentrations, up to $3,000 \mathrm{ppm} \mathrm{SO}_{2}$ were added to the oxidiser. Figure 6a shows the axial concentration profiles as determined for Lusatian dried lignite.

In the case of combustion with air, the reduction to $\mathrm{H}_{2} \mathrm{~S}$ can be seen after rapid $\mathrm{SO}_{2}$ release, whereby the maximum $\mathrm{H}_{2} \mathrm{~S}$ concentration forms after approx. $1 \mathrm{~m}$; approximately half of the sulphur then occurs as $\mathrm{H}_{2} \mathrm{~S}$. After complete addition of burnout air, all sulphur compounds oxidise to $\mathrm{SO}_{2}$. The dashed line indicated as $\left(\mathrm{SO}_{2}+\mathrm{H}_{2} \mathrm{~S}\right)_{\max }$ represents the concentration if full conversion of sulphur to the gas phase is assumed. The comparison with the measured values of $\left(\mathrm{SO}_{2}+\mathrm{H}_{2} \mathrm{~S}\right)$ shows how much sulphur is captured in the ash in the corresponding section. In the oxyfuel OF27 case, an $\mathrm{SO}_{2}$ concentration of 3,000 ppm was set in the oxidiser. This concentration is lower than the $\mathrm{SO}_{2}$ concentration of around 4,000 ppm measured at the reactor end. It corresponds with adequate accuracy to the concen- tration that will result due to the dilution by oxygen addition. As expected, the chemical speciation of the gaseous sulphur components is more on the side of the $\mathrm{SO}_{2}$. This corresponds to expectations, as the main proportion of the sulphur is added in the form of $\mathrm{SO}_{2}$ in the oxidiser. Nevertheless, the $\mathrm{H}_{2} \mathrm{~S}$ concentration doubles, obviously due to the reduction of $\mathrm{SO}_{2}$ to $\mathrm{H}_{2} \mathrm{~S}$ in the substoichiometric area. Following complete addition of the oxidiser, $\mathrm{H}_{2} \mathrm{~S}$ is, in turn, fully oxidised to form $\mathrm{SO}_{2}$.

The tests were also carried out under the same general conditions with Klein Kopje coal. Here, the chemical speciation of the sulphur in the substoichiometric range differed significantly. Whereas, at best $15 \%$ of the sulphur was detected in the form of $\mathrm{H}_{2} \mathrm{~S}$ in the case of Klein Kopje coal, the corresponding value for Lusatian dried lignite was around $25 \%$ to more than $50 \%$, whereby the concentrations are also significantly higher due to the higher sulphur content. This is shown as a comparison in Fig. $6 \mathrm{~b}$ for these two fuels for the air and the oxyfuel OF27 case. The supplement "0" or "3,000" indicates the $\mathrm{SO}_{2}$ concentration in ppm in the oxidiser (the case of air with $3,000 \mathrm{ppm} \mathrm{SO}_{2}$ in the combustion air and the oxyfuel case without $\mathrm{SO}_{2}$ in the oxidiser has no practical significance).

By way of summary, it was determined that for both fuels in the oxyfuel case there are lower $\mathrm{H}_{2} \mathrm{~S}$ proportions in
Fig. 6 Sulphur chemistry (total stoichiometry, 1.15 ; burner stoichiometry, 0.75; residence time in the primary zone, $3 \mathrm{~s}$ ). a Concentration profiles for gaseous sulphur compounds and oxygen (Lusatian dried lignite). b Chemical speciation of the gaseous sulphur compounds in the substoichiometric range

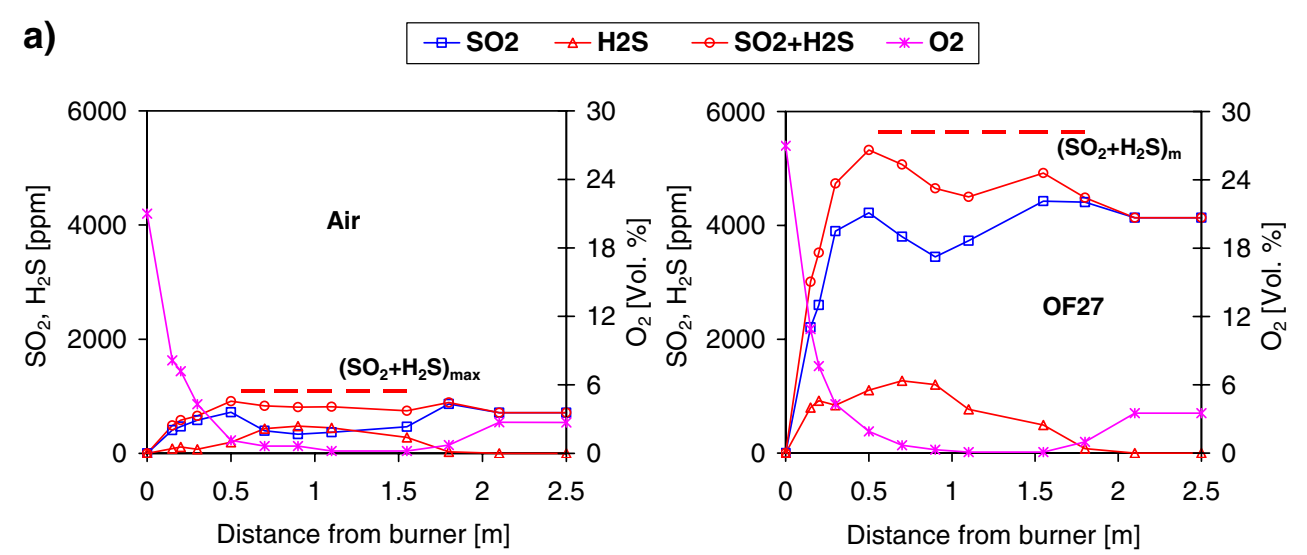

b)

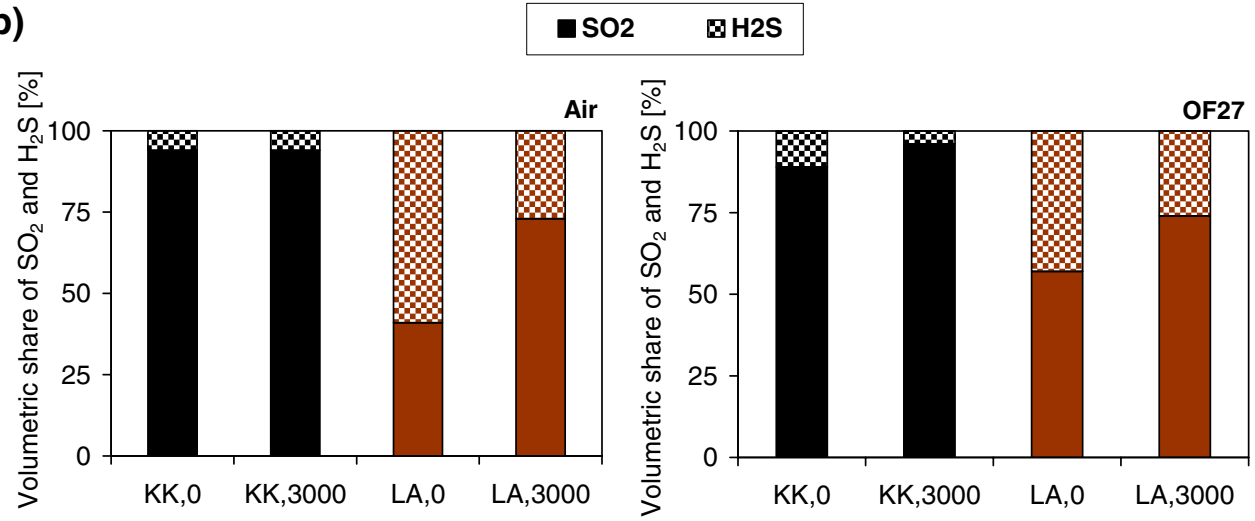


relation to the total gaseous sulphur in comparison with the air case. Nonetheless, the $\mathrm{H}_{2} \mathrm{~S}$ concentrations in the oxyfuel case are significantly increased. Over and above this, a considerable influence of the fuel on the chemical speciation of the gaseous sulphur can be determined - in both the air and oxyfuel cases. This certainly requires additional investigation.

Numerous tests, including tests of the characteristics of the sulphur components using the oxyfuel method, were also carried out on the 500-kW test facility (Mönckert et al. 2007a, 2007b). Recently, $\mathrm{SO}_{3}$ measurements were carried out here. The initial provisional results are shown in Fig. 7a. The measurements were carried out in the flue gas at approx. $450^{\circ} \mathrm{C}$ flue gas temperature. $\mathrm{An} \mathrm{SO}_{3}$ measurement on the clean gas side could not be carried out, as undershooting the dew point locally within the dust collector could not be avoided, falsifying the results.

Figure $7 \mathrm{a}$ shows the results achieved under air- and oxyfuel operation. As expected, the $\mathrm{SO}_{2}$ and $\mathrm{SO}_{3}$ concentrations in the oxyfuel case are higher than those in the air case. However, a higher rate of conversion of $\mathrm{SO}_{2}$ to $\mathrm{SO}_{3}$ can also be seen in the oxyfuel case, as represented by the linear graph.

In two respects, this affects the acid dew-point temperature. First of all, the acid dew-point temperature increases due to the higher $\mathrm{SO}_{3}$ concentration. Secondly, the increased steam content in the oxyfuel case also contributes to a further increase of the dew-point temperature. These relationships are shown in Fig. 7b, whereby the familiar Verhoff equation (Verhoff and Banchero 1974) was used to calculate the dew-point temperature.

The results achieved up to this point in time leave some unanswered questions. In particular, the fuel or ash properties have a considerable influence on the results achieved. Investigations should continue here. In addition, the measuring equipment used needs to be clarified further.

\section{Influencing the impurities in liquid $\mathrm{CO}_{2}$}

As can be seen in Fig. 1, alongside the $\mathrm{CO}_{2}$, there is also approximately 11 vol.\% of ballast gas in the dry flue gas that, on the one hand, significantly increases the energy requirement for liquefaction and, on the other hand, is dissolved partly in the liquid $\mathrm{CO}_{2}$. In accordance with current knowledge, a large portion of the impurities comes from the excess oxygen and the air leakage. The total amount of impurities in the liquefied $\mathrm{CO}_{2}$ will lie in the range of 1 to $4 \mathrm{~mol} \%$ depending on the selected pressure and temperature level during liquefaction (Kather et al. 2006). Alongside this, a portion of the classical harmful gases $\mathrm{NO}_{X}$ and $\mathrm{SO}_{2}$ will dissolve in the liquid $\mathrm{CO}_{2}$. The calculations of the amount of impurities dissolved in the liquid $\mathrm{CO}_{2}$ are based on the assumption that the chemical equilibrium will be reached (Köpke and Eggers 2007). However, as experience has shown that this depends on the design of the flow processes, the influence of kinetics on these condensation processes is currently being investigated. The question as to how the impurities dissolved in the $\mathrm{CO}_{2}$ diminish the operation of storage is the object of current and future research, which means that results in this connection can only be expected in the midterm. As the economic efficiency of the oxyfuel process will depend decisively on the required purity of the $\mathrm{CO}_{2}$ to be stored, the sources of the impurities are to be identified and possible minimisation measures indicated below have to be taken into consideration.

Origin of the impurities and their reduction potential

\section{Fuel composition}

The nitrogen bound in the coal contributes to the $\mathrm{N}_{2}$ concentration in the flue gas and to the formation of nitrogen oxides. Although the $\mathrm{NO}_{X}$ emissions related to the firing rate will be lower in the oxyfuel process, the $\mathrm{NO}_{X}$ concentration in the flue gas will be higher than in the airoperated comparison process. Based on the results shown above, $\mathrm{NO}_{X}$ concentrations in the dry flue gas upstream of the $\mathrm{CO}_{2}$ liquefaction of about $750 \mathrm{mg} / \mathrm{m}^{3}$ (stp, dry) could be expected, which corresponds to 1.5 times the concentration in the flue gas of the previously referenced RPP NRW study, where a value of $<500 \mathrm{mg} / \mathrm{m}^{3}$ (stp, dry) is applied (the $\mathrm{NO}_{X}$ performance depends strongly on the fuel rank
Fig. $7 \quad \mathrm{SO}_{3}$ conversion and acid dew-point temperature. a Measured $\mathrm{SO}_{2}$ and $\mathrm{SO}_{3}$ concentrations on the $500-\mathrm{kW}$ test facility under air- and oxyfuel operation with Lusatian dried lignite (measurements performed at $450^{\circ} \mathrm{C}$ flue gas temperature). b Acid dew-point temperature depending on the $\mathrm{SO}_{3}$ content and the steam concentration a)

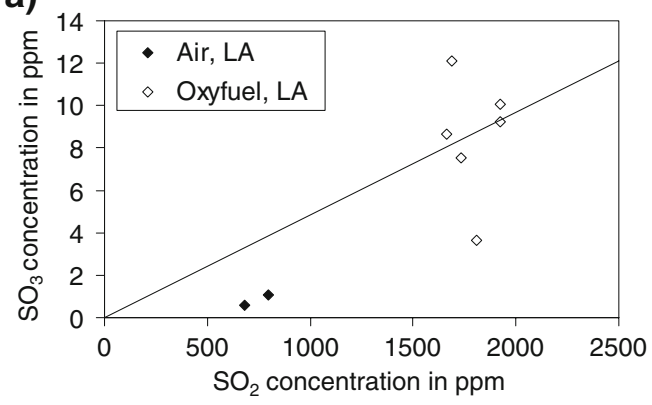

b)

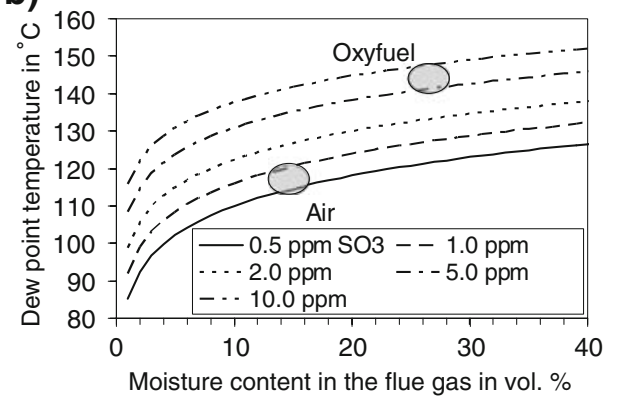


and the selected burner and firing system. The given numbers are related to the RPP NRW burning South African coal).

The sulphur present in the coals reacts on combustion with oxygen to form above all sulphur dioxides. Whereas the $\mathrm{SO}_{2}$ concentration in the RPP NRW is applied with $<3,950 \mathrm{mg} / \mathrm{m}^{3}$ (stp, dry), it increases in the oxyfuel process due to similar relationships in the same way as for nitrogen oxides to approx. $8,570 \mathrm{mg} / \mathrm{m}^{3}$ (stp, dry; with South African hard coal).

\section{Excess oxygen during combustion}

As already indicated, the uneven distribution of the coal to the individual burners means that today an excess oxygen of at least $15 \%$ is necessary to ensure coal burnout and also to prevent an increased risk of corrosion attacks to the furnace walls. The resulting oxygen content in the dry flue gas of 4.55 vol.\% could be reduced to approx. $3-3.5$ vol.\% by means of costly and complex measurements of the coal mass flows to the individual burners. It might then be possible to achieve an excess oxygen of $10 \%$ (Oxy Combustion Processes for $\mathrm{CO} 2$ Capture from Power Plant, 2005).

\section{Purity of the oxygen provided}

The impurities of the oxygen supplied by a cryogenic airseparation unit at $99.5 \mathrm{vol} \%$ purity consist almost exclusively of argon and at $95 \mathrm{vol} . \%$ purity, the impurities consist of argon (approx. 3.8 vol.\%) and nitrogen (approx. 1.2 vol.\%). As both substances are inert, it is assumed in accordance with today's level of knowledge that their proportions in the liquid $\mathrm{CO}_{2}$ during transport and on storage of the $\mathrm{CO}_{2}$ underground will have no negative effects. During liquefaction of the $\mathrm{CO}_{2}$, on the other hand, they increase the energy demand, using up a portion of the power requirement saved with the airseparation unit, a cause of the reduced purity. Thus, specifying the purity of the oxygen is essentially an optimisation task with regard to the power requirements of the air-separation unit and $\mathrm{CO}_{2}$ liquefaction. With regard to combustion, the nitrogen proportions introduced as impurities of the oxygen into the furnace could cause a slight increase in the nitrogen oxides. At any rate, the flue gas loss is increased due to the impurities.

\section{Air leakage}

All that the atmospherically driven steam generators have in common is the entire flue gas path from burner outlet to the induced-draught fan are operated under pressure lower than the ambient pressure in order to prevent particulates and flue gases from escaping. As the flue gas paths of today's steam generators are not designed as absolutely gastight, above all, for reasons related to economy, certain quantities of leakage air enter the system. The classical locations for this leakage air entry in the case of PF firing are, above all, the connections to the burner cases at the water wall, the bottom ash extractor, the ash removal in the flue gas path, as well as manholes, viewing hatches, and measuring points at a wide variety of positions. There is also a certain amount of leakage air via the ash removal from the electrostatic precipitator. The controlled air introduced into the system in the form of cooling, sealing, or purging air, in addition to those uncontrolled leakage air, should be replaced in the oxyfuel process by dry recirculation gas that is withdrawn upstream of the $\mathrm{CO}_{2}$ liquefaction.

In the case of conventional power stations, the leakage air influences the power station efficiency only to the extent that non-preheated air is fed to the furnace. As the measurement of the residual oxygen content means that the excess air is kept constant, the forced draught fan is controlled to deliver less air. This reduces the air volume fed to the air pre-heater, which leads to a slight rise in the flue gas temperature behind the air pre-heater and flue gas losses. However, the drops in efficiency caused by this are so low that no appreciable efforts have been made to reduce leakage air that occurs to a moderate degree. As it is practically impossible to measure and record leakage air flow, the actual quantity of leakage air is not known exactly and can only be estimated. For new power stations under construction today, it is assumed that the leakage air proportion is around $2 \%$ to $4 \%$ of the total flue gas volume and that it will rise to around $10 \%$ over the years.

In the case of the oxyfuel process, on the other hand, the leakage air has considerably greater disadvantages that can no longer be neglected, as the nitrogen that enters increases the power demand for $\mathrm{CO}_{2}$ liquefaction and decreases the $\mathrm{CO}_{2}$ purity. The leakage mass flows depend:

- on the differential pressures between the flue gas in the boiler and ducts and the ambient; and

- on the geometric dimensions of the boiler and the ducts.

As it can be assumed that these two influencing variables in an oxyfuel power station will be similar to those for the air-operated comparison process up to the recirculation branch, the leakage air proportion for the oxyfuel process is not related to the significantly smaller flue gas mass flow that is routed downstream of the recirculation branch towards the $\mathrm{CO}_{2}$ liquefaction, which is only approx. 33\% of the total flue gas mass flow, but is related to the total flue gas mass flow upstream of the recirculation branch in the same way as for steam generators with air-operated combustion systems. Therefore, the leakage air proportion $\alpha$ is defined as follows:

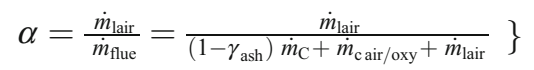

Here, $\dot{m}_{\text {flue }}$ is the flue gas mass flow, $\dot{m}_{\mathrm{C}}$ is the fuel mass flow, $\dot{m}_{\text {lair }}$ is the leakage air flow, $\dot{m}_{\text {cair/oxy }}$ is the controlled 
and fed air mass flow in the air-operated comparison process and/or the total of the controlled and fed oxygen and recirculation mass flows for the oxyfuel process, and $\gamma_{\text {ash }}$ is the ash content of the fuel.

Figure 8 shows the influence of the different sources of impurity on the $\mathrm{CO}_{2}$ concentration that can be achieved in the dry flue gas. This clearly indicates that leakage air has a severe influence. With an leakage air proportion of $\alpha=3 \%$, a maximum $\mathrm{CO}_{2}$ concentration of 83.7 vol.\% would result in the dry flue gas, even if the oxygen purity upon which the process is based were to be $99.5 \%$ and the excess oxygen were reduced to $10 \%$; currently, this is not possible nowadays for PF firing. In order to keep the impurities in the liquid $\mathrm{CO}_{2}$ as well as the power requirement for liquefaction as low as possible, a $\mathrm{CO}_{2}$ concentration in the dry flue gas of at least $90 \%$ should be achieved. With the excess oxygen of $15 \%$ that is currently achieved and an oxygen purity of $99.5 \%$, the leakage air must be reduced to a value of less than $1 \%$ (see Fig. 8). This should be possible by means of corresponding constructive measures.

\section{Flue-gas cleaning}

The most favourable solution from the point of view of the economy and the efficiency rate for $\mathrm{CO}_{2}$ removal would be compression of the dry flue gas to approx. 100 bar and subsequent storage underground. Neither a denitrification plant nor a flue gas desulphurisation system is needed, but most of the $\mathrm{NO}_{X}$ and the $\mathrm{SO}_{2}$ will be captured along with the compressed $\mathrm{CO}_{2}$. However, as the included impurities

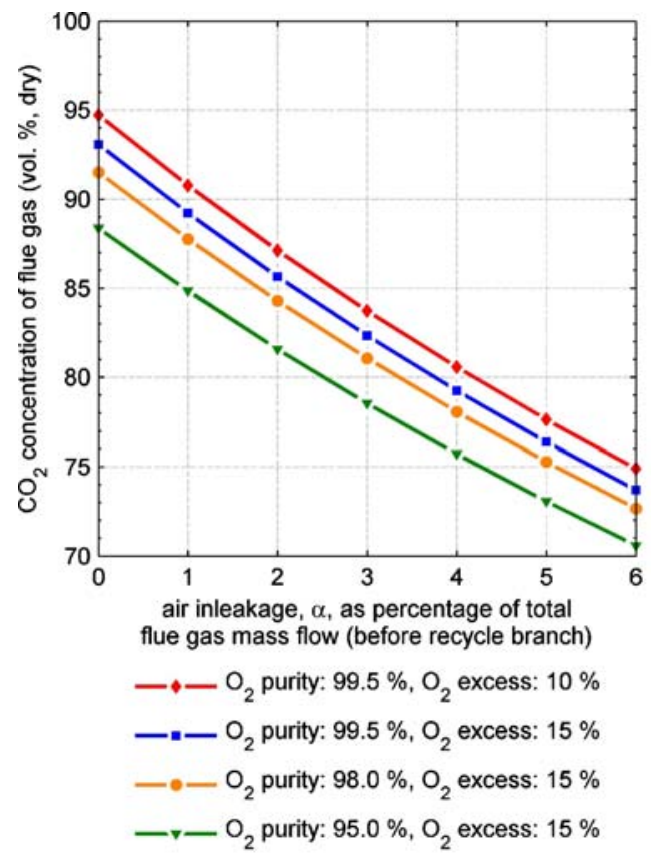

Fig. 8 Influence of the different sources of impurities on the $\mathrm{CO}_{2}$ concentration that can be achieved in the dry flue gas of oxygen, $\mathrm{NO}_{X}$, and $\mathrm{SO}_{2}$ appear too high from today's perspective, it is assumed that at least an increase in the concentration of the $\mathrm{CO}_{2}$ by means of cryogenic liquefaction has to be carried out. Here, the $\mathrm{NO}_{X}$ and $\mathrm{SO}_{2}$ proportions are to be found almost exclusively in the liquid $\mathrm{CO}_{2}$, which means that neither $\mathrm{NO}_{X}$ nor $\mathrm{SO}_{2}$ have to be removed from the exhaust gas. However, if the kinetic leads to lower capturing of $\mathrm{SO}_{2}$ and $\mathrm{NO}_{X}$ in the liquid $\mathrm{CO}_{2}$ and an association of higher concentrations of these two components in the residual gas, sulphur and nitrogen would only have to be removed from a mass flow rate of approx. $3-4 \%$ - related to the flue gas mass flow upstream of the flue gas recirculation branch.

If the requirements for purity of the liquid $\mathrm{CO}_{2}$ are higher, $\mathrm{NO}_{X}$ and $\mathrm{SO}_{2}$ concentrations can be reduced by means of corresponding flue gas cleaning systems upstream of the $\mathrm{CO}_{2}$ liquefaction. If the $\mathrm{NO}_{X}$ concentrations of $200 \mathrm{mg} / \mathrm{m}^{3}$ (stp, dry) and $\mathrm{SO}_{2}$ concentrations of $200 \mathrm{mg} / \mathrm{m}^{3}$ (stp, dry) that are normal today, e.g. in Germany, had to be achieved in the dry flue gas upstream of the $\mathrm{CO}_{2}$ liquefaction, the technologies of the denitrification based on selective catalytic reaction (SCR; capture efficiency of up to $90 \%$ ) known today and the wet flue gas desulphurisation system (capture efficiency of up to $98.5 \%$ ) would be sufficient. However, the oxidation of the desulphurisation product to sulphate in the flue gas desulphurisation system must take place separately so that no other unwanted gases are added to the flue gas mass flow. This design results in the SCR and the desulphurisation plant having to be configured for a flue gas mass flow that is around ten times the size compared to the untreated flue gas compression design. The capture efficiency of a SCR plant that is common today, with normal efforts and an $\mathrm{NH}_{3}$ slip of $1.5 \mathrm{ppm}$, is a maximum of $90 \%$. An improvement in the uneven distribution in the flue gas flow while accepting a higher pressure loss could slightly improve the capture efficiency with unchanged $\mathrm{NH}_{3}$ slip. The capture efficiency of today's desulphurisation plants is limited to approx. $99 \%$. At assumed concentrations of $9,000 \mathrm{mg} / \mathrm{m}^{3}$ (stp, dry) $\mathrm{SO}_{2}$ and $1,300 \mathrm{mg} / \mathrm{m}^{3}$ (stp, dry) $\mathrm{NO}_{X}$ on the entry side of the flue gas cleaning system arranged downstream of the flue gas recirculation branch, loads in the dry flue gas upstream of the $\mathrm{CO}_{2}$ liquefaction of approx. $90 \mathrm{mg} / \mathrm{m}^{3}$ (stp, dry) $\mathrm{SO}_{2}$ and $100-130 \mathrm{mg} / \mathrm{m}^{3}$ (stp, dry) $\mathrm{NO}_{X}$ would result. In the liquid $\mathrm{CO}_{2}$, this leads to concentrations of approx. 57 ppm $\mathrm{SO}_{2}$ and approx. 34 ppm $\mathrm{NO}_{X}$ under equilibrium conditions. The $\mathrm{NO}_{X}$ concentration could be further reduced by routing the SCR reactor into the total mass flow upstream of the flue gas recirculation branch, a precursor for enlarging a $\mathrm{DeNO}_{X}$ plant by a factor of 3 to approx. $16 \mathrm{ppm} \mathrm{NO}_{X}$ in the liquid $\mathrm{CO}_{2}$. With all the concentrations stated, it must be borne in mind that they are based on equilibrium calculations and kinetically dominat- 
ed operations can lead to deviations. Any influences of compression and water removal within the intercoolers are not taken into account. The relevant investigations are the object of current research.

The concentration of the oxygen in the liquid $\mathrm{CO}_{2}$ is very high in all cases and not effected by SCR and FGD. If this is unacceptable for storage, rectification processes could be deployed to reduce the oxygen concentration in the liquid $\mathrm{CO}_{2}$; however, whereby an additional drop in efficiency of at most $0.5 \%$ points is caused.

\section{$\mathrm{CO}_{2}$ liquefaction}

The separation of the $\mathrm{CO}_{2}$ from the flue gas is achieved by means of condensation. Subsequently, the captured $\mathrm{CO}_{2}$ is compressed to around 100 bar and fed off via a pipeline. For the condensation, the pressure and temperature of the flue gas has to be changed in such a way that the dew point of the flue gas is reached and the $\mathrm{CO}_{2}$ starts to condense. As the flue gas is not pure $\mathrm{CO}_{2}$, rather a mixture of multiple components, the condensation stops if the pressure and temperature are unchanged. This makes it necessary for a reasonable $\mathrm{CO}_{2}$ capture rate either to increase the flue gas pressure or to lower the flue gas temperature compared with the condensation of pure $\mathrm{CO}_{2}$. Equilibrium calculations show that it is more favourable to lower the flue gas temperature than to increase the flue gas pressure, as in this case fewer inert gases are dissolved in the $\mathrm{CO}_{2}$. However, the flue gas temperature is limited downwards by the triple point of the $\mathrm{CO}_{2}$ at $-56.6^{\circ} \mathrm{C}$. A shortfall leads to the formation of solid $\mathrm{CO}_{2}$ (dry ice) and the condenser would block.

The $\mathrm{CO}_{2}$ condensation must be configured in such a way that the amount of permitted impurities in the liquid $\mathrm{CO}_{2}$ is not exceeded. At the same time, the economy of the entire oxyfuel process requires a certain minimum $\mathrm{CO}_{2}$ capture rate. Both the $\mathrm{CO}_{2}$ purity and the minimum $\mathrm{CO}_{2}$ capture rate are not precisely defined. However, as both variables are dependent (see Fig. 9), only one variable can

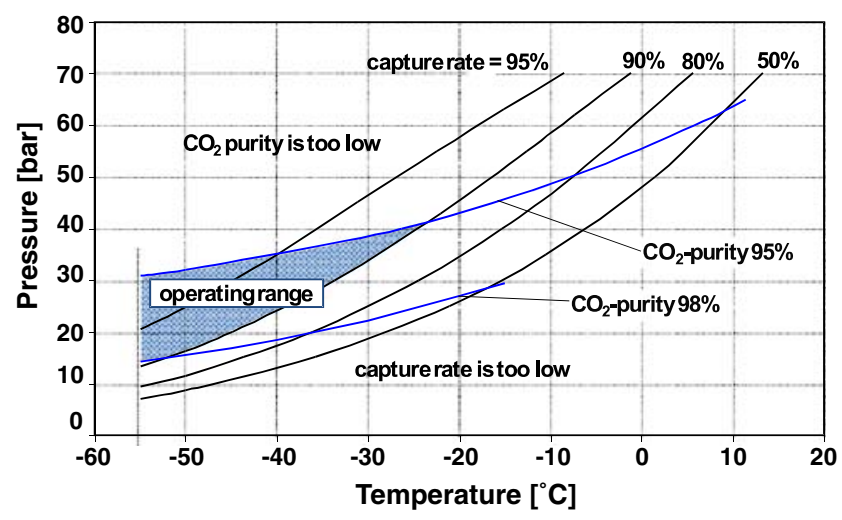

Fig. 9 Calculated $p, T$ diagram for the single-level condensation of $\mathrm{CO}_{2}$ from the flue gas of the oxyfuel process be selected without restriction. As a general principle, Fig. 9 also indicates that capture rates above $90 \%$ and purities above $95 \%$ require temperatures that are significantly below $-30^{\circ} \mathrm{C}$ and pressures between 16 and 42 bar. Whereas the flue gas compression can be carried out easily by means of multi-stage flue gas compressors, there are a number of technical possibilities to generate the low temperatures. At operating temperatures around $0^{\circ} \mathrm{C}$ and below, it must be borne in mind that water in the flue gas has to be completely removed to prevent malfunctions due to ice formation or $\mathrm{CO}_{2}$ hydrates.

1. Flue gas dehumidification

Flue gas dehumidification must take place in at least two stages. In the first stage, the flue gas is cooled down so that most of the water vapour present condenses. The water cannot be completely removed by this process, as the minimum cooling water temperature in the power station sets the saturation partial pressure of the water vapour. Halogen and sulphur compounds as well as nitrogen oxides also dissolve in the condensate partially. The exact amount of dissolved gases cannot currently be determined due to the complex flue gas composition and possible impairment of the equilibrium state. The residual moisture is further reduced by the downstream flue gas compression and intermediate cooling. Despite this, subsequent deployment of an adsorbing agent is necessary for residual dehumidification.

\section{Generating low temperatures}

Generating temperatures up to $-55^{\circ} \mathrm{C}$ with refrigerating machine compressors and $\mathrm{NH}_{3}$ as refrigerant is the state-ofthe-art. Due to the large mass of flue gas, cooling power in the middle two-digit megawatt range is required. The utilisation of low-temperature waste heat that can no longer be linked to the water-steam cycle for electric power generation could be another alternative to supply an absorption refrigerating machine. An additional possibility is the internal utilisation of the captured $\mathrm{CO}_{2}$ as a refrigerant. All three possibilities have advantages and disadvantages.

\section{- Compression-type refrigeration}

The deployment of $\mathrm{NH}_{3}$ compression-type refrigerating systems in the single-digit megawatt range is the state-ofthe-art. Their modular design means they provide the possibility to run the condensation process on various temperature levels, lowering the energy requirement for liquefaction. Above all, at very low refrigerant temperatures, the coefficient of performance of the compression refrigeration circuit falls severely; this can be reduced by using multiple stages. A disadvantage is the additional 
technical overhead in the form of additional refrigeration circuits and refrigerating machine compressors. The deployment of $\mathrm{CO}_{2}$ as refrigerant, above all to reduce the size, is conceivable but it is not the state-of-the-art in these dimensions.

\section{- Absorption-type refrigeration}

Absorption refrigeration systems enable generation of the same temperatures as $\mathrm{NH}_{3}$ refrigerating machine compressors with the help of heat and a low proportion of electrical energy. The temperature level and the amount of heat required rise with falling cooling temperature, which means that for deployment in the power station process, an exact energetic but also economic assessment between the electric power and refrigeration generation from the available heat quantities must take place. As they have fewer moving parts, absorption refrigeration systems feature high reliability with low electrical power requirement.

\section{- Internal cooling}

From a technical perspective, the utilisation of the liquefied $\mathrm{CO}_{2}$ as refrigerant involves the least additional overhead. The $\mathrm{CO}_{2}$ separated under high pressure is reduced in a throttle to a lower pressure so that there is a certain temperature difference in relation to the compressed flue gas in the condenser. The lower boiling temperature of the liquefied $\mathrm{CO}_{2}$ is used to condense it out of the flue gas. This expanded $\mathrm{CO}_{2}$ completely evaporates in the condenser. Therefore, the gaseous $\mathrm{CO}_{2}$ now has to be compressed in a second compressor to pipeline pressure. As malfunctions in the flue gas system-e.g. due to changes in the flue gas composition-directly influence the properties and amount of the available refrigerant in this configuration, the technical feasibility in the required size still has to be examined in order to be able to reliably exclude above all blocking of the system due to dry ice.

As already explained, during the cryogenic liquefaction, the $\mathrm{CO}_{2}$ capture rate and the $\mathrm{CO}_{2}$ purity are directly dependent upon one another. The maximum $\mathrm{CO}_{2}$ purity at high capture rates is limited, above all, due to the leakage air proportion, the excess oxygen, and the oxygen purity. Pressure staging during the condensation process means that the $\mathrm{CO}_{2}$ purity can be kept stable, even at higher flue gas pressures, in favour of a higher condensation temperature. Alternatively, at a constant condenser temperature, multi-stage condensation can achieve a significant enhancement of the $\mathrm{CO}_{2}$ purity. Any additional $\mathrm{CO}_{2}$ purity requirements are only possible by distilling the liquid $\mathrm{CO}_{2}$. As a part of the previously liquefied $\mathrm{CO}_{2}$ must be evaporated again during distillation, the $\mathrm{CO}_{2}$ capture rate falls and the specific energy requirement for the $\mathrm{CO}_{2}$ separation rises. However, the purity can be increased to far more than $99 \%$ if required.

\section{Summary}

The oxyfuel process in the form examined here is based on the familiar steam power cycle. The combustion takes place in an $\mathrm{O}_{2}-\mathrm{CO}_{2}-\mathrm{H}_{2} \mathrm{O}$ atmosphere with moderating the furnace temperatures by flue gas recirculation leading to similar furnace and steam generator designs compared with existing PF units. However, the subsequent flue gas treatment requires adaptations.

Heat balance requirements result in an increased oxygen concentration when mixing the oxygen with the recycled flue gas. With this higher oxygen concentration similar burn-off courses and a similar burnout is observed if compared with conventional air combustion. With regard to NO formation and its reduction in the furnace under the general conditions of an oxyfuel combustion system, the comprehensive investigations permit the conclusion to be drawn that the existing technologies developed for conventional air combustion can also be applied under oxyfuel conditions to efficiently reduce the nitrogen oxides. The NO mass flows are significantly reduced in comparison with the conventional air-operated method under oxyfuel conditions. Due to a characteristic in the oxyfuel process, the concentrations of various species increase significantly in the furnace. This naturally also applies to gas components with corrosive effect. As the results show, higher $\mathrm{H}_{2} \mathrm{~S}$ concentrations result in the furnace from the flue gas recirculation, preferably under reducing conditions. Higher $\mathrm{SO}_{3}$ concentrations also result, whereby the mechanism must be investigated further. These facts and the circumstance that under oxyfuel conditions the moisture content in the flue gas rises significantly could mean that the risk of corrosion rises in both the high- and low-temperature ranges.

By separating the atmospheric nitrogen from the oxygen carrier fed into the furnace with the help of a cryogenic airseparation unit, the dry flue gas consists of up to $90 \% \mathrm{CO}_{2}$ and can be liquefied with reasonable efforts. However, in the process other substances, e.g. oxygen, $\mathrm{NO}_{X}$ and $\mathrm{SO}_{2}$, enter the liquid phase. These substances, above unknown concentrations, could lead to problems with transport and underground storage of the $\mathrm{CO}_{2}$.

Therefore, the success of the oxyfuel process depends decisively on the level of impurities in the liquid $\mathrm{CO}_{2}$ that must be adhered to. These impurities can be influenced by the upstream systems of steam generator and flue-gas cleaning. Whereas the $\mathrm{NO}_{X}$ and $\mathrm{SO}_{2}$ concentrations in the liquid $\mathrm{CO}_{2}$ can be reduced by means of the flue gas cleaning systems upstream of liquefaction, for the oxygen content, this is only possible using low excess oxygen.

The oxygen purity achieved in the air-separation unit and, above all, the air leakage that occurs in the flue gas system lead to a rise in the inert components argon and 
nitrogen, which increase the energy demand for $\mathrm{CO}_{2}$ liquefaction. An energetic-economic optimum between airseparation unit, leakage air, and $\mathrm{CO}_{2}$ liquefaction must be found here.

Acknowledgements Some of the results were achieved within the framework of the EU research project ENCAP (ENCAP-Project Enhanced capture of CO2 (2007) http://www.encapco2.org accessed on Dec. 2007). Another part of the work was financed via the COORETEC alliance projects "ADECOS" and "Corrosion and slagging in hightemperature power plants with new materials" (COORETEC research programme (2007) http://www.cooretec.de accessed on Dec. 2007). These works were supported by the European Commission, the [German] Ministry of Economics and the project executing organisation in Jülich, and the utility companies and manufacturers involved. Furthermore, the authors would like to thank in particular Messrs. Bhupesh Dhungel, Christian Hermsdorf, Mathias Klostermann, René Kull, Jörg Maier, Karl Mieske and Patrick Mönckert.

Open Access This article is distributed under the terms of the Creative Commons Attribution Noncommercial License which permits any noncommercial use, distribution, and reproduction in any medium, provided the original author(s) and source are credited.

\section{References}

Al-Makhadmeh L, Maier J, Scheffknecht G (2009) Coal Pyrolysis and Char Combustion under Oxy-Fuel Conditions. 34th International Technical Conference on Coal Utilization \& Fuel Systems, Clearwater, Florida, USA, May 31-June 4, 2009

Andersson K, Johnsson R, Hjartstam S, Johnsson F, Leckner B (2008) Radiation intensity of lignite-fired oxy-fuel flames. Experimental Thermal and Fluid Science 33:67-76

Aroonwilas A, Veawab A (2006) Integration of $\mathrm{CO}_{2}$ capture unit using single- and blended-amines into supercritical coal-fired power plants: implications for emission and energy management. GHGT 8, June 19-22, 2006, Trondheim, Norway

Blokh AG (1987) Heat transfer in steam boiler furnaces. Hemisphere, Washington

Darde A, Prabhakar R, Tranier J-P, Perrin N (2009) Air separation and flue gas compression and purification units for oxy-coal combustion systems. Energy Procedia 1:527-534
Dhungel B, Mönckert P, Maier J, Scheffknecht G (2007) Investigation of Oxy-Coal Combustion in Semi-technical Test Facilities. Third International Conference on Clean Coal Technologies for our Future-CCT 2007, May 15-17, 2007, Cagliari, Italy

Forzatti P (2001) Present status and perspectives in de-NOx SCR catalysis. Applied Catalysis A: General 222:221-236

Kather A, Hermsdorf C, Klostermann M, Mieske K, Eggers R, Köpke $\mathrm{D}$ (2006) Konzept für ein $600 \mathrm{MW}_{\mathrm{el}}$ Steinkohlekraftwerk mit $\mathrm{CO}_{2}$-Abtrennung auf der Basis des Oxyfuel-Prozesses. 38. Kraftwerkstechnisches Kolloquium 2006, Oct. 24-25, 2006, Dresden

Kather A, Hermsdorf C, Klostermann M (2007) Der kohlebefeuerte Oxyfuel-Prozess - Grundlagen zur Dampferzeugergestaltung und Möglichkeiten zur Verminderung der Verunreinigungen im $\mathrm{CO} 2$. VGB PowerTech 4/2007:84 - 91

Kather A, Rafailidis S, Hermsdorf C, Klostermann M, Maschmann A, Mieske K, Oexmann J, Pfaff I, Rohloff K, Wilken J (2008) Research \& development needs for clean coal deployment. IEA Clean Coal Centre Report Nr. CCC/130, London

Kluger F, Maier J, Hein KRG, König J, Brüggemann H, Priesmeier U (2001) Verbrennung von vorgetrockneter Braunkohle (TBK)Experimentelle Untersuchung feuerungstechnischer Maßnahmen zur Stickoxidreduktion. VDI-Berichte 1629:77-85

Köpke D, Eggers R (2007) Experimentelle Untersuchungen des Phasengleichgewichts des Systems Kohlendioxid/Argon und Literaturauswertung zum System Kohlendioxid/Schwefeldioxid. Chemie Ingenieur Technik 79:1235-1239

Maier J, Dhungel B, Mönckert P, Scheffknecht G (2007) Combustion and emission behaviour under oxy-fuel condition. 39. Kraftwerkstechnisches Kolloquium 2007, Oct. 11-12, 2007, Dresden

Mieske K, Kather A (2007) Experimentelle Untersuchung der Schadstoffentstehung bei der Verbrennung im Oxyfuel-Prozess. VDI-Berichte 1988:69-74

Mönckert P, Reber D, Maier J, Scheffknecht G (2007a) Operation of a Retrofited 0.5 $\mathrm{MW}_{\text {th }}$ PF Combustion Facility under Oxyfuel Conditions-An Experience Report. $32^{\text {rd }}$ International Technical Conference on Coal Utilization \& Fuel Systems, Clearwater, Florida, USA, June 10-15, 2007

Mönckert P, Reber D, Maier J, Scheffknecht G (2007b) Verhalten von Stickoxiden bei der Oxyfuel-Verbrennung mit Rauchgasrezirkulation. VDI-Berichte 1988:81-88

Oxy Combustion Processes for $\mathrm{CO}_{2}$ Capture from Power Plant (2005) IEA Greenhouse Gas R \& D Programme, Report Number 2005/9

Pulverised Coal Oxycombustion Power Plants, Volume 1 Bituminous Coal to Electricity (2008) Final Report, DOE/NETL-2007/1291

Verhoff FH, Banchero JT (1974) Predicting dew points of flue gases. Chem.Eng.Prog 70:71-72 